\title{
A Periodic Assessment System for Urban Safety and Security Considering Multiple Hazards Based on WebGIS
}

\author{
Xuexi Chen ${ }^{1,2}$, Guohua Chen ${ }^{1,2, *}$, Qin Yang ${ }^{1,2}$, Jialing $\mathrm{Li}^{1,2}$, Zhi Yuan ${ }^{2,3}$ and Saihua Jiang ${ }^{1,2}$ \\ 1 Institute of Safety Science \& Engineering, South China University of Technology, Guangzhou 510640, China; \\ 201921003307@mail.scut.edu.cn (X.C.); 201821003444@mail.scut.edu.cn (Q.Y.); \\ 202121004271@mail.scut.edu.cn (J.L.); meshjiang@scut.edu.cn (S.J.) \\ 2 Guangdong Provincial Science and Technology Collaborative Innovation Center for Work Safety, \\ Guangzhou 510640, China; yuanzhibj@163.com \\ 3 Guangdong Academy of Safety Science and Technology, Guangzhou 510060, China \\ * Correspondence: mmghchen@scut.edu.cn
}

Citation: Chen, X.; Chen, G.; Yang, Q.; Li, J.; Yuan, Z.; Jiang, S. A Periodic Assessment System for Urban Safety and Security Considering Multiple Hazards Based on WebGIS.

Sustainability 2021, 13, 13993.

https://doi.org/10.3390/su132413993

Academic Editors: Ghassan Beydoun, Siti Hajar Othman and Dedi I. Inan

Received: 26 September 2021 Accepted: 14 December 2021 Published: 18 December 2021

Publisher's Note: MDPI stays neutral with regard to jurisdictional claims in published maps and institutional affiliations.

Copyright: $\odot 2021$ by the authors. Licensee MDPI, Basel, Switzerland. This article is an open access article distributed under the terms and conditions of the Creative Commons Attribution (CC BY) license (https:// creativecommons.org/licenses/by/ $4.0 /)$.

\begin{abstract}
With the frequent occurrence of various disasters and accidents, realizing the periodic assessment and visualization of urban safety and security considering multiple hazards is of great significance for safe urban development. In this paper, a periodic assessment system is developed for urban safety and security considering multiple hazards, based on WebGIS. This system consists of an assessment module, a visualization module, and an assistant module that integrates the assessment model to process the assessment data quickly and realizes the visualization of a thematic map and data statistics for rationalizing assessment results. The assessment of a typical urban area was carried out to prove that the created system can effectively conduct periodic assessments and support single-hazard and multi-hazard analysis and auxiliary decision-making. This system can be applied to the grid management and periodic assessment of urban areas at different levels, with high expansibility and application value. It can also help to promote the sustainable construction of a safe and smart city.
\end{abstract}

Keywords: urban safety and security; multiple hazards; assessment system; periodicity; WebGIS

\section{Introduction}

With the advancement of urbanization around the world, the scale of cities continues to expand. According to United Nations statistics, by 2018, about 4.2 billion people were living in cities worldwide and the world urbanization rate had reached $55 \%$, showing a trend that continued upward [1]. The increasing complexity of urban operational systems has ushered in unprecedented opportunities and impetus. Meanwhile, cities are also facing a variety of new problems and challenges. Among them, frequent natural disasters and technological accidents have a particularly prominent impact on urban safety [2]. These include natural disasters such as the bush fires in Australia in December 2019, the severe typhoon, Vamco, that hit Manila in the Philippines in November 2020, and the catastrophic flood in Henan Province, China in July 2021, as well as technological accidents such as the explosion of chemical storage tanks in Jiangsu, China in March 2019, the explosion of sodium nitrate stored in a depot in Lebanon in August 2020, and the major road traffic accident in Sao Paulo State, Brazil in November 2020. All of these incidents caused serious personal and property loss and posed a huge threat to urban safety and security. How to deal with the risk of natural disasters and technological accidents, while improving the effectiveness of urban safety and security management, is a hot topic of research nowadays.

The research on urban safety and security mainly revolves around assessment workthat is, assessing the risk faced by an urban area, or the resilience or capacity of the area itself to characterize the degree of urban safety and security, then proposing management measures or suggestions. 
The research into disaster risk mainly assesses natural disasters and technological accidents. In terms of natural disasters, Ghosh et al. [3] used the flood hazard and vulnerability indicators alongside geographic information system (GIS) to assess the flood risk in combination with the AHP method; Kim et al. [4] identified the natural disaster index and building information, established the typhoon vulnerability functions, and estimated the loss caused by the disaster; Lin et al. [5] built a risk assessment index system comprising three aspects, hazard, sensitivity, and vulnerability, to assess the risk of flood disaster in mountainous scenic spots in Fujian Province; Boukri et al. [6] used risk assessment tools to assess the risk of earthquake in urban areas of Algeria, and drew the data into a risk map by GIS; Akinola et al. [7] used a hazard assessment model to assess forest fire risk in Missouri, based on several measurable environmental parameters influencing forest fire vulnerability; Dabanli [8] obtained the drought risk index for provinces of Turkey by multiplying the drought hazard index and drought vulnerability index. In terms of technological accidents, Granda et al. [9] carried out a fire risk assessment for the historical center of Guimaraes in Portugal by using the index-based method, and used GIS to map vulnerability and risk for spatial analysis; Lee et al. [10] proposed a risk assessment model that predicts the degree of hazard and severity of toxic substance leakage accidents by applying different exposure coefficients depending on gender and age; Basheer et al. [11] provided a template for conducting quantitative risk assessments of facilities storing hazardous chemicals by calculating the accident incidence and outcome frequencies and the probability of damage; Bondžić et al. [12] constructed the risk assessment method for HAZMAT road accidents using the parameters of hazard, exposure, and vulnerability. Guinet et al. [13] proposed an approach to evaluate the most crowded places to conduct the hospital's vulnerability assessment. Azari et al. [14] proposed a quantitative method to evaluate the urban gas pipeline risk considering the social and structural parameters of urban blocks. In summary, the objects of risk-based assessment mainly include natural disasters such as flooding, typhoons, earthquakes, forest fire, and drought, as well as technical accidents such as urban fire, hazardous chemical accidents, crowded place accidents, urban gas pipeline accidents, and so on. Such studies mainly use single or multiple elements, such as vulnerability, hazard, sensitivity, exposure, or other influencing elements to characterize risk using an index function or weighted calculation method. Some of them also use GIS tools to visually display the risk map. The researches based on risk assessment considers the threat of one or more types of hazards faced by urban areas, but there is a lack of consideration about the weakening effect of risk control capacity and emergency capacity on disaster risk.

The research into resilience or capacity mainly assesses the capabilities of the city itself. Gromek et al. [15] developed an urban infrastructure resilience assessment model based on the resilience of physical features, the structure and environment, the organization, the economy, and the law to guide urban resilience enhancement, whereas Moradi et al. [16] constructed an index system from the five dimensions of social, cultural, physical, environmental, and economic to evaluate the resilience of Mashhad. Feofilovs et al. [17] introduced a dynamic urban resilience to a natural hazards assessment tool able to compare different urban resilience scenarios, with an output in the form of an index score; however, Cardoso et al. [18] developed a resilience assessment framework directing and facilitating an objective-driven resilience diagnosis of urban cities and services. Ottai [19] established an emergency capacity assessment framework from the two dimensions of disaster preparedness and disaster relief capacity, and evaluated the existing emergency capacity of the Kingdom of Saudi Arabia; Yang et al. [20] constructed the assessment index of urban emergency capacity in terms of three parts, namely, pre-prevention capacity, in-process coping capacity, and post-event recovery capacity. Arambepola et al. [21] conducted a capacity assessment method that considered likely post-disaster needs and evaluated the potential earthquake risk scenario in Dhaka city; Chisty et al. [22] developed a coping capacity assessment framework by integrating the individual's and actual community's potential disaster-coping capacity; and Anantsuksomsri et al. [23] assessed the natural disaster coping capacity of urban residents with social capital approach and applied it to 
the case study of Bangkok. In summary, the objects of resilience-based or capacity-based assessment are mainly the management system and hardware facilities of the city's disaster prevention and reduction. These studies mainly use the social, physical, environmental, economic, legal, and other influencing elements of urban areas, as well as many influencing aspects, such as prevention capacity, disaster-relieving capacity, and recovery capacity to characterize the urban resilience or capacity. The calculation methods are mainly the index system method and weighted method. The research, based on resilience or capacity assessment, considers a city's resistance to disasters and post-disaster recovery capacity but there is a lack of consideration about the deviation between the actual risk and the capacity for disasters.

At the present stage, the assessment of urban safety and security still focuses on a single element and a single hazard type, and the assessment method is also relatively mature. However, due to the characteristics of concentrated hazard-bearing bodies and diverse types of risk sources in urban areas, an assessment with a single element or a single disaster type cannot comprehensively reflect the safety and security degree of urban areas [24]. Therefore, comprehensive and coupled assessment research for multiple hazards and multiple elements is becoming a hot spot for extensive exploration [25]. Tiepolo et al. [26] constructed 48 indicators representing hazard, exposure, vulnerability, and adaptability, and carried out a region-wide multi-hazard assessment for Mauritanian communities; Khatakho et al. [27] separately assessed and superimposed hazards such as flood, landslide, earthquake, and urban fire, and obtained a multi-hazard risk assessment in the Kathmandu Valley of Nepal. Gallina et al. [28] proposed a multi-hazard assessment method, integrating the climate-related factors of hazard, exposure, and vulnerability into spatial units and time scales, conducted disaster analysis and created rankings through an impact matrix and index evaluation. Barria et al. [29] proposed a multi-analysis method that uses matrixes to cross the exposure and vulnerability of flood, landslide, tsunami, and earthquake, and applied it to two coastal cities in Chile. Depietri et al. [30] established a multi-hazard assessment method to evaluate the vulnerability and risk of heatwaves, inland flooding, and coastal flooding in New York City; Bixler et al. [31] presented a methodology for a multi-hazard risk assessment combining exposure to multiple natural hazards and social vulnerability, and applied to a case in Austin, Texas, USA; and Araya-Muñoz et al. [32] developed a multi-hazard assessment methodology that integrates 32 indicators of exposure and sensitivity, and assessed the multiple hazards in the Concepción Metropolitan Area, Chile. In terms of regional urban safety and security assessment, the method of multiple hazards analysis considers the comprehensive impact of various natural disasters and technological accidents in urban areas, so the risk it reflects is closer to the actual situation. The method of multiple elements analysis uses vulnerability, hazard, exposure, adaptability, coping capacity, and other elements to characterize the risk or capacity of urban areas. Compared with the single-element analysis method, it can reflect the level of risk or capacity more comprehensively. In addition, urban safety and security are affected by both risk and capacity. Considering the control effect of the city's capacity on urban risk can make the assessment results of urban safety and security closer to the actual situation. In summary, a multiple hazards and multiple elements analysis method that considers the effect of both risk and capacity can reflect the level of urban safety and security more comprehensively and objectively.

Although multi-hazard and multiple element research can more objectively reflect the degree of urban safety and security, the amount of basic research data is large, and the calculation steps are numerous. Traditional calculation methods require a long assessment time, and the results are not intuitive enough. With the development of computer technology, the Geographic Information System (GIS) has been widely used in urban planning, transportation, disaster assessment, and many other fields due to its powerful analytical and visualization functions [15], which can assist researchers in rapid calculation and assessment. However, because the direct application of GIS requires the mastery of professional knowledge and skills in software, an ordinary user may find it difficult to 
use. The secondary development of GIS and Web integration has become a hot topic in current system development. Professional calculation and analysis are integrated into the development packages or codes, and there is no need for users to perform specialized operations, which makes GIS applications more interactive and operable [33]. Dolce et al. [34] developed a WebGIS platform known as the observed damage database, which used scatter plot coloring to present the data distribution of population and buildings, and used twodimensional partition rendering to present the distribution of large earthquake intensity; Abdalla et al. [35] proposed a fuzzy risk assessment method for flooding, supported by 3D-GIS, using the digital elevation model to conduct hydraulic simulations for different flow scenarios, and the magnitude of flood risk was expressed through 3D hydrological conditions; Cui et al. [36] developed a storm surge hazard assessment system based on the seed spread algorithm and visualized the flood route of the Tianjin Binhai New Area. Elsewhere, Azevedo et al. [37] developed a risk assessment system based on WebGIS, which provided hazard, vulnerability, and risk assessment maps for oil spills in coastal areas; Giovinazzi et al. [38] developed a WebGIS Decision Support System to assess earthquakeinduced physical damages and the resulting impacts on the functions of historic areas and to monitor their resilience; and Coletti et al. [39] proposed an automatic approach to comprehensive risk assessment and developed a WebGIS software system to visualize the results. The development of the WebGIS system has been applied in many research fields, but the development of and research into urban safety and security assessment systems for multiple hazards are relatively rare. At present, urban area assessment systems for a single hazard are still the mainstay.

In order to conduct a more comprehensive and accurate assessment, display the results visually, and carry out more efficient and extensive applications, the authors propose an urban safety and security assessment model that considers the combined effect of comprehensive risk in terms of the triggering relationship and the emergency capacity under the event evolution for multiple hazards [40]. A periodic assessment system for urban safety and security considering multiple hazards, based on WebGIS, is developed. The assessment system is implemented using Java Server Pages (JSP) and web front-end development technology, consisting of an assessment module, visualization module, and assistant module. The system can realize a periodic assessment for urban safety and security and visualize the assessment results via thematic maps and data statistics. The application was carried out for a typical urban area, the spatial distribution of the assessment results was obtained, and the results of single-hazard and multi-hazard assessments were analyzed and discussed. The system can be applied to the grid management and periodic assessment of urban areas at different levels and has high expansibility and application value, which is conducive to promoting the construction and sustainable development of safe and smart cities.

\section{Framework for the Assessment System}

Since the periodic assessment of urban safety and security considering multiple hazards is characterized by multiple objects, multiple data, multiple models, and multiple judgment mechanisms, the assessment system needs to adopt a mode of multi-terminal network transmission for data exchange. It can highly integrate models and judgment mechanisms and build a visualization interface through GIS services. The assessment theory behind the system is based on risk and capacity, carrying out multi-hazard assessment combined with the inherent risk, residual risk, prevention and control capacity, and the emergency capacity of various hazard events. Based on the idea of "multi-terminal, high integration and visualization", the framework of the system is designed including the system structure, development framework, and theoretical framework.

\subsection{System Architecture}

The WebGIS-based system development architecture is mainly divided into client/server $(\mathrm{C} / \mathrm{S})$ and browser/server (B/S) [33]. The B/S architecture has the characteristics of wide 
distribution, low cost, easy development and maintenance, and simple operation, which is more suitable for multi-terminal network transmission. Therefore, the assessment system is developed using the B/S architecture, combining Web and GIS technology to build the structural framework of the system, which consists of the presentation layer, business layer, and data layer, as shown in Figure 1. The presentation layer is used to handle the interface display and interaction of multiple terminals such as PC and mobile devices, and send requests and responses to the Web server and GIS server through the Hypertext Transfer Protocol (HTTP). The business layer is used to handle the requests and responses from the presentation layer and to the data layer, select Tomcat and ArcGIS Server as the logical processing carriers, and make requests to the basic information database and the geographic information database, respectively, through Java database connectivity (JDBC) and the spatial data engine (ArcSDE). The data layer is used to store and manage the fundamental data of the system. MySQL and SQL Server databases are used to manage the basic information and geographic information, respectively, which can realize the fast and stable transmission of the fundamental data. These three layers can integrate and visualize the data provided by multiple terminals. Cyclic data interaction can be carried out between each layer, which can support the requirements for rapid periodic assessment and visualization rendering of the system.

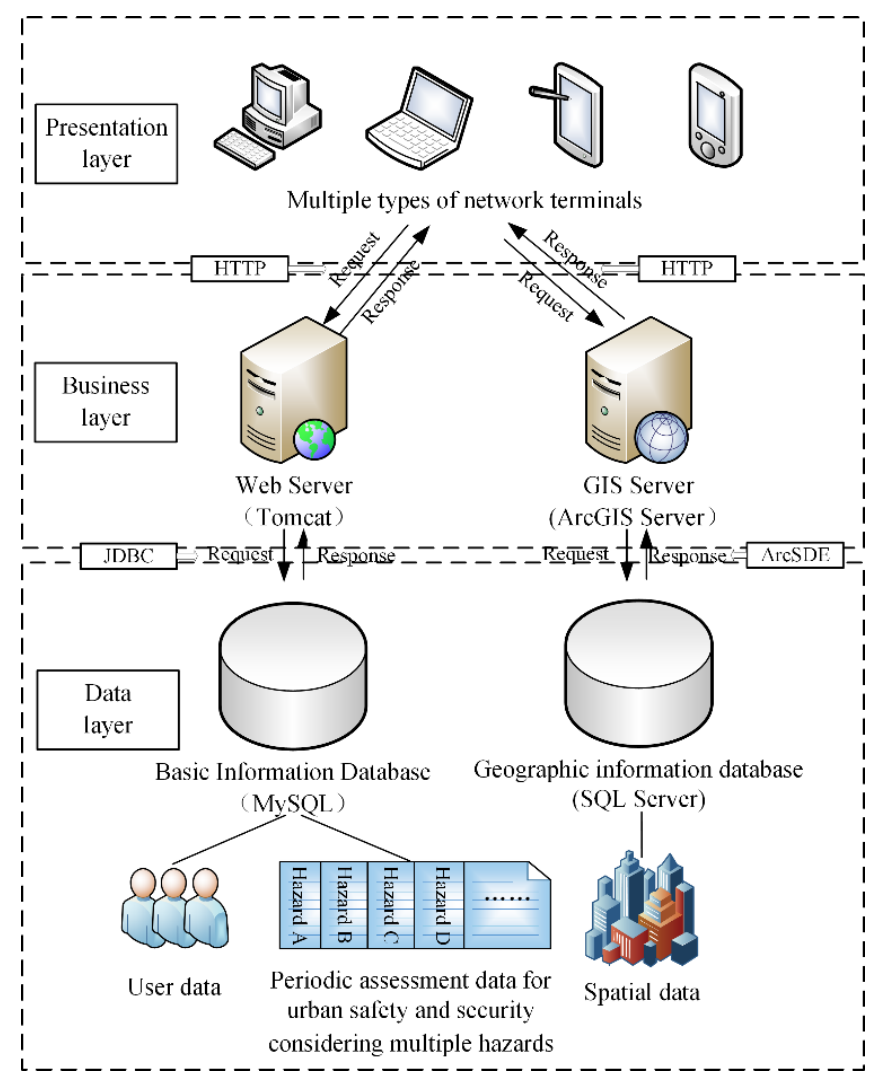

Figure 1. The architecture of the assessment system.

\subsection{Development Framework}

The WebGIS-based system requires various open-source frameworks and libraries to successfully achieve professional development and maintenance [41]. The rigidity of traditional development methods makes it difficult to maintain and expand web applications. However, the Model-View-Controller (MVC) pattern proposed by Trygve Reenskaug effectively solves the problem of independent module development, due to its characteristic of loosen-coupling, which greatly improves the efficiency of development and maintenance [42]. The assessment system selects the most mature and stable MVC pattern, 
called "Struts", and uses the combination of "JavaBean-JSP-Servlet" to build the system development framework.

As shown in Figure 2, the system development framework consists of three modules, View, Controller, and Model, which are interrelated but independent of each other. "View" is the front-end interface, which is used for direct interaction with users, passing their requests to the controller and receiving response information from the model, using JSP, HTML, CSS, JavaScript, and other front-end programming languages to display the web interface. "Controller" uses servlet to interpret and transmit users' commands, employing Java to construct the transmission interface. "Model" uses servlet to process the instructions transmitted, uses JavaBean components to encapsulate the program objects, realizes repeated calls to the model through the encapsulation of configuration, and sends the processed results to the view interface.

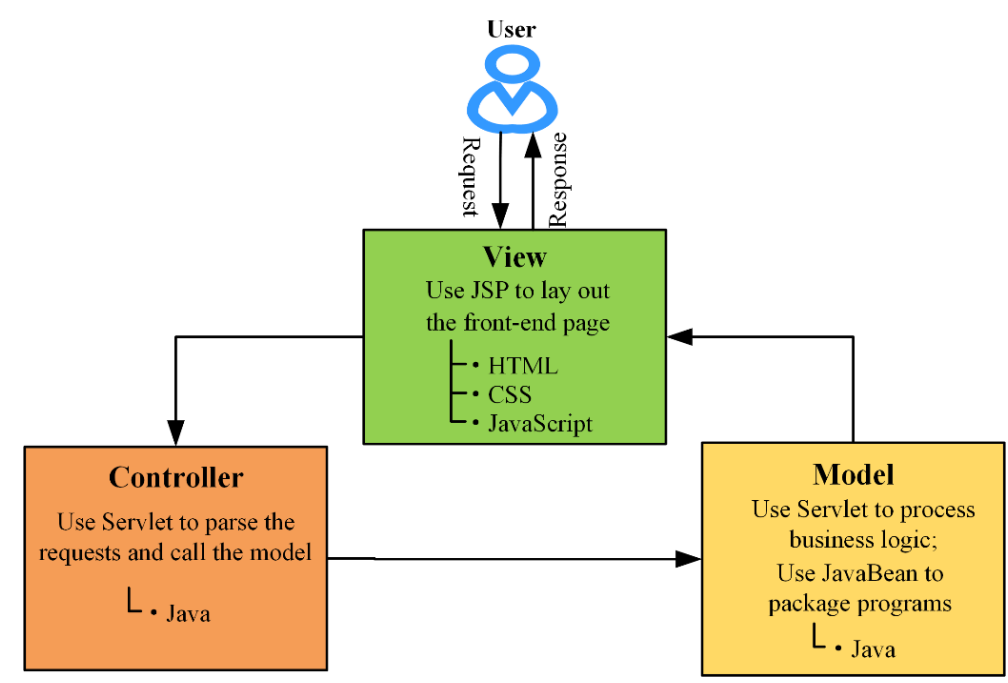

Figure 2. Development framework of the assessment system.

\subsection{Theoretical Framework}

The theoretical basis of urban safety and security assessment is risk theory [40]. The United Nations International Strategy for Disaster Reduction stated that disaster risk management achieves sustainable development by implementing disaster-risk reduction policies that prevent the emergence of new disaster risk, reduce inherent risk, manage residual risk, and help to enhance resilience [43-45]. Therefore, comprehensive risk management, integrating risk prevention and control and emergency management, can strengthen the risk reduction of potential and actual hazard events in urban areas. From the perspective of comprehensive risk management, the degree of urban safety and security is jointly determined by the risks, prevention and control capacity, and emergency capacity of hazard events. The risks can be divided into inherent risk and residual risk. According to the basic risk quantitative expression of the United Nations, the inherent risk is determined by the hazards in various events and the vulnerability of the hazard-bearing bodies. Prevention and control capacity includes risk prevention capacity and source control capacity. The risk that still exists after taking prevention and control measures is called residual risk. The emergency capacity is measured in four stages: preparedness, response, coping, and recovery. For the key hazard events, considering the control effect of emergency capacity on residual risk, the comprehensive impact of the two determines the degree of urban safety and security.

According to the relationship between the influencing elements, a theoretical assessment framework of the system can be constructed, as shown in Figure 3. Firstly, the inherent risk assessment for a single hazard event is carried out; the assessment grade is obtained, and then a judgment is made as to whether it is a key hazard event. Secondly, the residual risk is assessed and the grade is obtained by combining the inherent risk with the 
prevention and control capacity. Thirdly, the emergency capacity is assessed and the grade is obtained by integrating the capacity elements of the four stages. Fourthly, the grades of residual risk and emergency capacity are combined to obtain the safety and security grade of a single hazard event. At last, according to the grade of inherent risk, the safety and security grade of each key hazard event is integrated to establish the grade of urban safety and security considering multiple hazards.

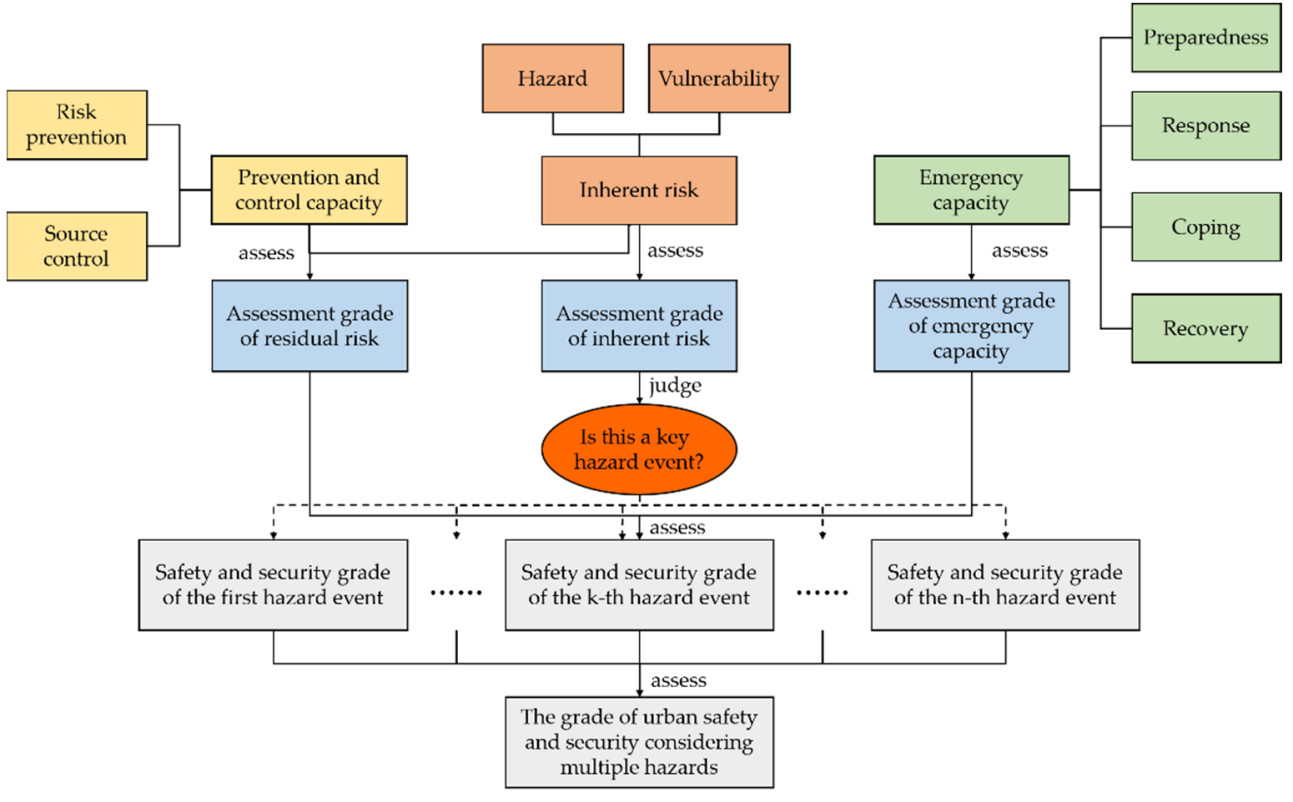

Figure 3. The assessment theoretical framework.

\section{Development and Implementation of the Assessment System}

\subsection{System Function Module}

Since periodic assessment for urban safety and security considering multiple hazards involves various objects, data, models, and judgment mechanisms, the traditional assessment methods would take up a lot of computing time. Data collection and sorting would be cumbersome, making it difficult to present assessment results intuitively. Therefore, the system needs to meet the requirements of rapid calculation and judgment for the basic data, then obtain the assessment results simultaneously. At the same time, the assessment results should be visualized intuitively and rapidly in the form of thematic maps and statistical charts that provide feedback for periodic assessment. Finally, to improve the human-computer interaction experience and the necessary security protection for the system, it is helpful to add user registration and login, and this helps documentation. As shown in Figure 4, the function modules of the assessment system can be divided into three modules: the assessment module, the visualization module, and the assistant module.

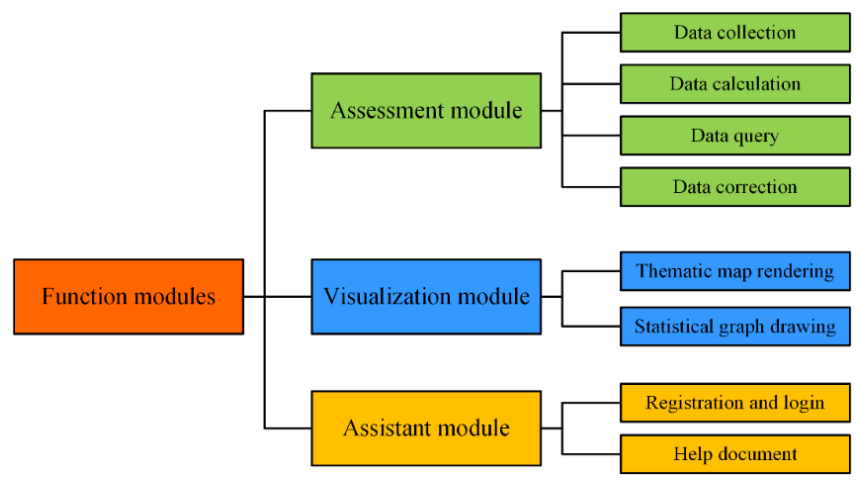

Figure 4. Function modules of the assessment system. 


\subsection{Assessment Module}

The assessment module is one of the core modules of the system and realizes numerous functions, such as data collection, calculation, query, and correction. This module mainly applies JSP and asynchronous Javascript and XML (AJAX) to solve the interaction problem of front-end and back-end data streams. The original data (i.e., the third-class indicators) obtained from data collection are stored in the database while synchronous calculations are performed to obtain the assessment result data (i.e., the first-class indicator). Multi-level queries can be performed on the assessment results against the assessment result database, which can then be output to the visualization module. According to the feedback of the visualization module, data correction can be performed against the original database. The assessment results can be updated synchronously by updating the original data circularly, achieving a periodic assessment. The logic behind each function of the assessment module is shown in Figure 5.

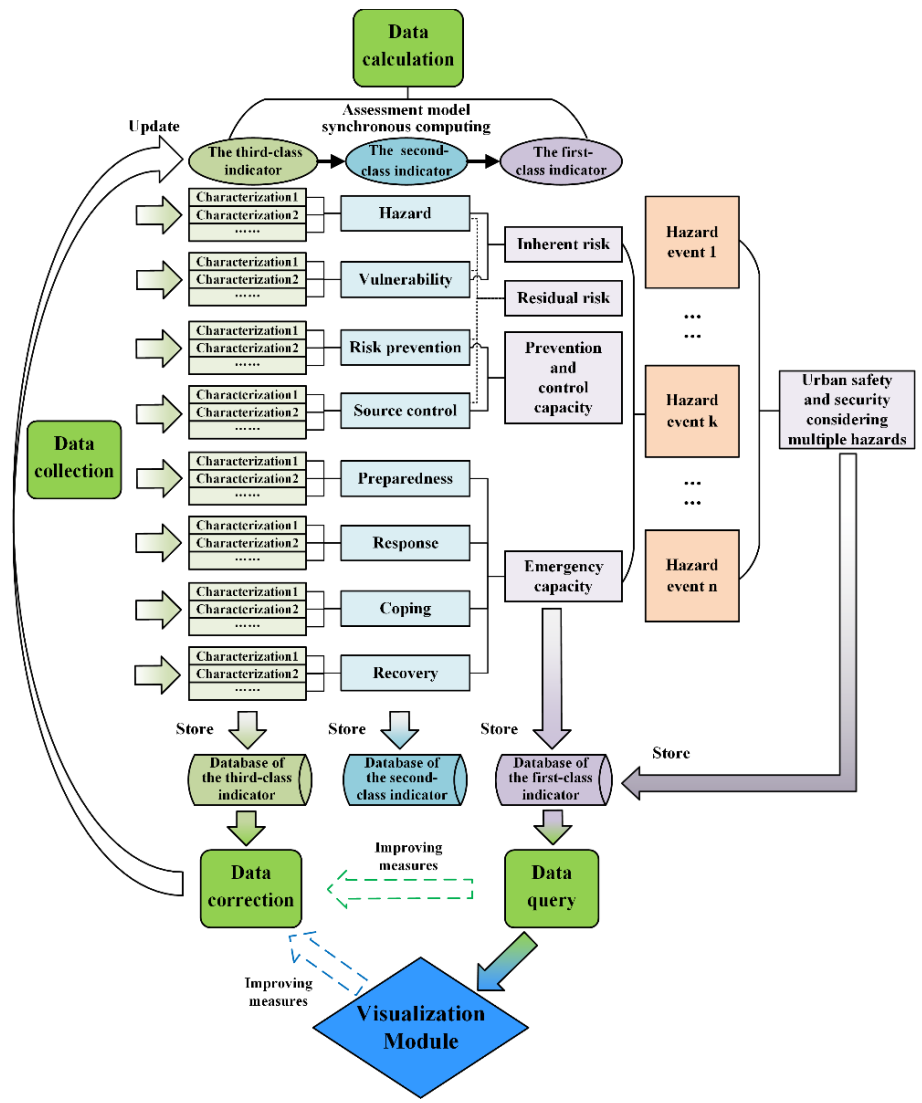

Figure 5. The logic between each function of the assessment module.

\subsubsection{Data Collection}

The assessment system requires the collection of basic data from multiple assessment units and multiple hazards, which is characterized by a large number of assessment objects and collected data. The development based on the B/S structure realizes multi-user collaborative online operation. The data collection ports are widely distributed, and the data are collected comprehensively by scattered network terminals, which greatly improves the collection efficiency of original data. Some original data are quantitative, while some are semiquantitative. Quantitative data are collected directly by users, according to regional monitoring stations and specific statistics. Semiquantitative data are collected by the user through judgment criteria. The data collection function is developed based on JSP technology. By inputting the assessment time, unit, and index data of each hazard in the unit, the original data are transmitted to the specified Servlet program in the server. Then, 
the MySQL database is accessed for original data storage, and the original data wait to be called as the input value of the data calculation function.

\subsubsection{Data Calculation}

From the comprehensive risk management perspective, the authors' existing research proposed the concept of "comprehensive screening, key analysis, and comprehensive evaluation" for urban safety and security assessment, and then established an urban safety and security assessment method for multiple hazards that considers the combined effect of the comprehensive risk in terms of the triggering relationship and the emergency capacity under the conditions of event evolution [40]. According to the method, the degree of urban safety and security is jointly determined by the risks faced by the city (divided into inherent risk and residual risk), the prevention and control capacity, and the emergency capacity of hazard events. The urban safety and security assessment model considering multiple hazards consists of the inherent risk assessment model, the residual risk assessment model, the emergency capacity assessment model, and the urban safety and security model considering multiple hazards assessment. The calculation flow and assessment model are shown in Figure 6.

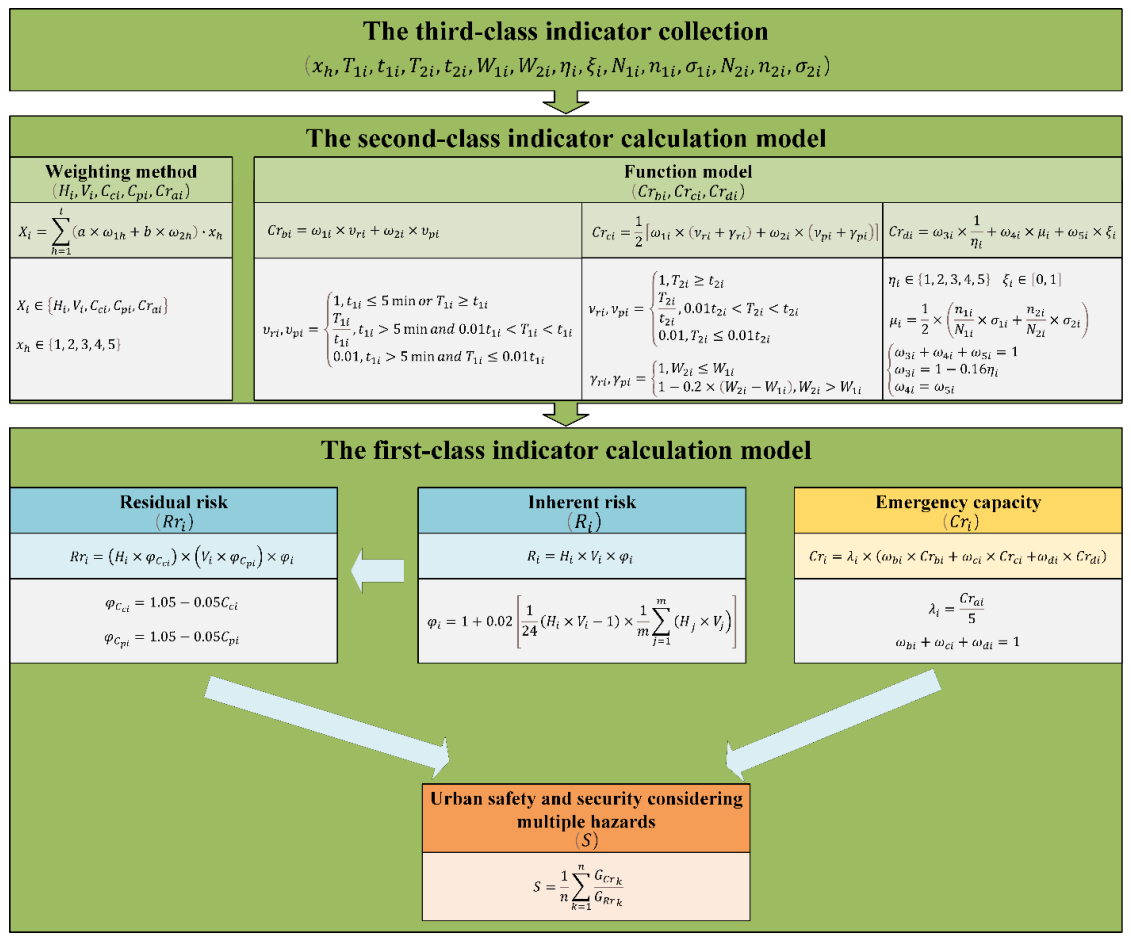

Figure 6. The calculation flow and assessment model.

In this model, urban safety and security considering multiple hazards $(S)$, inherent risk $\left(R_{i}\right)$, residual risk $\left(R r_{i}\right)$, and emergency capacity $\left(C r_{i}\right)$ are the first-class indicators. $R_{i}$ is determined by the second-class indicators of hazard $\left(H_{i}\right)$ and vulnerability $\left(V_{i}\right)$. Prevention and control capacity include source control capacity $\left(C c_{i}\right)$ and risk prevention capacity $\left(C p_{i}\right)$. $R r_{i}$ is determined by $H_{i}, V_{i}, C c_{i}$, and $C p_{i}$. Cr $r_{i}$ is determined by the second-class indicators: preparedness capacity $\left(C r_{a i}\right)$, response capacity $\left(C r_{b i}\right)$, coping capacity $\left(C r_{c i}\right)$, and recovery capacity $\left(\mathrm{Cr}_{d i}\right)$.

The first-class indicators are calculated by the second-class indicators through the function model. In the inherent risk assessment model, $\varphi_{i}$ is introduced as the risk amplification coefficient of a single hazard event, which is determined by $H_{i}$ and $V_{i}$ of all the events, with the range from 1 to 1.5. In the residual risk assessment model, the normalized coefficients $\varphi_{C c i}$ and $\varphi_{C p i}$ are introduced, which are calculated from the values of $C c_{i}$ and $C p_{i}$, with the range from 0.8 to 1 . In the emergency capacity assessment model, $\lambda_{i}$ is 
introduced as the reliability coefficient, which is calculated from the value of $C r_{a i}$, with the range from 0.2 to $1 ; \omega_{b i}, \omega_{c i}, \omega_{d i}$ are the weight values of $C r_{b i}, C r_{c i}$ and $C r_{d i}$. In the urban safety and security assessment model considering multiple hazards, the assessment value is weighted, calculated by the ratio of the emergency capacity grade to the residual risk grade of each key hazard event. For the first-class indicators, such as inherent risk, residual risk, emergency capacity, and urban safety and security considering multiple hazards, the "Grade 1-5" assessment standards were constructed to define their evaluation grade by using the natural break method.

The second-class indicators are calculated using the third-class indicators through the weighting method and function model. Some second-class indicators, such as $H_{i}$, $V_{i}, C c_{i}, C p_{i}$, and $\mathrm{Cr}_{a i}$, are calculated using their characterization indicators (i.e., the thirdclass indicators) through the combined weighting method; $\omega_{h 1}$ is a subjective weight value determined by the G1 method; $\omega_{h 2}$ is an objective weight value determined by the entropy weight method; $a$ and $b$ are the proportion of subjective and objective weight values, respectively; and $x_{h}$ presents the third-class indicators, for which " $1-5$ " scoring standards are established according to the selection of the actual indicators. The other second-class indicators, such as $\mathrm{Cr}_{b i}, \mathrm{Cr}_{c i}$, and $\mathrm{Cr}_{d i}$, are calculated by their characterization indicators through the function model. $v_{r i}$ and $v_{p i}$ represent the response efficiency, $v_{r i}$ and $v_{p i}$ represent the disposal efficiency, and $\gamma_{r i}$ and $\gamma_{p i}$ represent the disposal effects of personnel evacuation and professional disposal, respectively. $v_{r i}, v_{p i}, v_{r i}$ and $v_{p i}$ are determined by the ratio of the actual time $\left(t_{1 i}, t_{2 i}\right)$ to the optimal time $\left(T_{1 i}, T_{2 i}\right) ; \gamma_{r i}$ and $\gamma_{p i}$ are determined by the difference between the accident degree before disposal $\left(W_{1 i}\right)$ and the accident degree after disposal $\left(W_{2 i}\right) . \eta_{i}$ is the damage degree, $\mu_{i}$ is the social support degree, and $\xi_{i}$ is the government support degree, all of which are dimensionless parameters in the range from 0 to $1 . n_{1 i}$ and $n_{2 i}$ represent the number of people and properties covered by insurance; $N_{1 i}$ and $N_{2 i}$ represent the total number of people and properties affected; and $\delta_{1 i}$ and $\delta_{2 i}$ are the guarantee degree parameters with the range from 0 to 1 .

The data calculation function is developed based on JSP technology. The algorithm logic is constructed based on the mentioned model, which is directly configured in the specified servlet in the back-end server. By assigning the original data as input values, the calculation program is run, and the output results can be obtained, including the value and grade of inherent risk, residual risk, and the emergency capacity of each hazard event, as well as the value and grade of urban safety and security considering multiple hazards. MySQL is used to manage original data and assessment result data in separate libraries, which reduces the computing load on the server during circular calculation, and facilitates data query and correction.

\subsubsection{Data Query}

The object of the data query is assessment results, which are retrieved from the assessment results database. A multi-level classification query structure is used to build the query logic, and four query modes are constructed: "any time-any unit", "any timespecific unit", "specific time-any unit", and "specific time-specific unit". The data query function is developed based on AJAX technology, passing the values of assessment time, unit, and element entered in the front-end interface to the back-end servlet according to the mentioned query modes. The first-class indicators database is accessed, the data are obtained on demand, and the obtained assessment result dataset is returned to the frontend interface for classification and display through the callback function. The assessment value and grade of inherent risk, residual risk, and emergency capacity for each hazard event in each unit are all obtained, as well as the value and grade of urban safety and security considering multiple hazards for each unit. These assessment results can be output to the visualization module as the data information of visual rendering. 


\subsubsection{Data Correction}

The object of data correction is original data. According to the feedback from the visualization module or data query results, the original data can be corrected after taking improving measures. The "one unit, one modification" approach is adopted to construct the logic of data correction, and the "specific time-specific unit" mode is adopted to retrieve data from the original database. The data correction function is developed, based on JSP and AJAX technology. The values of inputted assessment time and unit are transferred to the back-end servlet via AJAX. The third-class indicators database is then accessed, and the demand dataset is obtained and returned to the front-end interface through the callback function. The data are corrected and submitted through the JSP form. Finally, the data calculation program is run and the original database and assessment result database are updated synchronously, in order to realize the correction and re-saving of the data.

The front-end interface for each function of the assessment module is shown in Figure 7.

\subsection{Visualization Module}

The visualization module is another of the core modules of the assessment system, which is used to process visualization effects such as thematic map rendering and statistical graph drawing of the assessment results. This module mainly applies ArcGIS API for JavaScript and the Apache ECharts open-source visualization chart library to solve the mapping problem between assessment result data and geographic data, providing chart statistics, thus realizing the two functions above. According to the key analysis for visualization results, this assists in making decisions on improvement measures of the assessment area and provides feedback to the assessment module for periodic assessment. Thematic map rendering requires pre-collecting geographic data of the assessment area, making a map of the area, and storing it in the geographic information database. The web server uses the assessment result data of the first-class indicators database, such as the assessment value or grade of inherent risk, residual risk, emergency capacity, and urban safety and security considering multiple hazards, which are connected with the GIS server to realize the mapping and rendering of the assessment result data. Statistical graph drawing directly uses the integrated chart library in the web server to realize the chart mapping of the assessment results. The functional logic of the visualization module is shown in Figure 8.

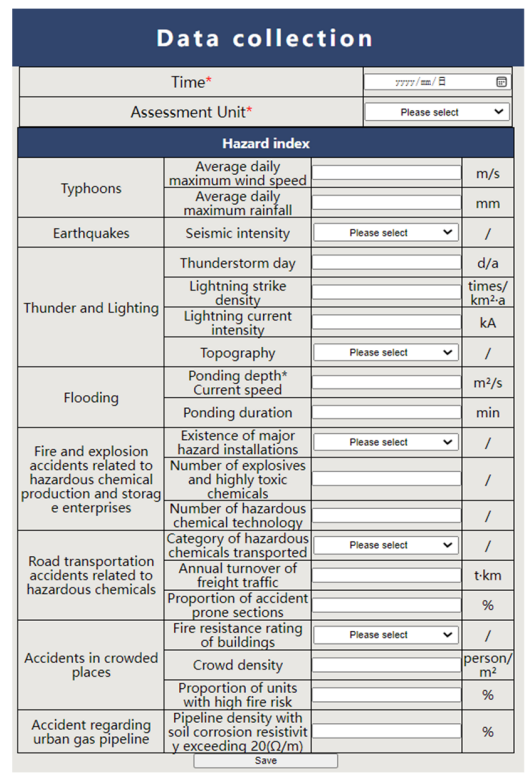

(a)

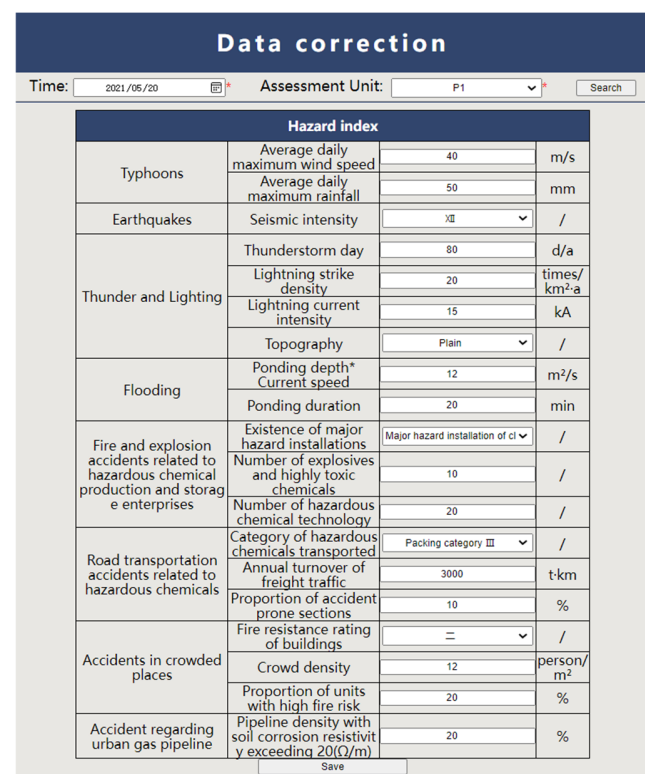

(b)

Figure 7. Cont. 


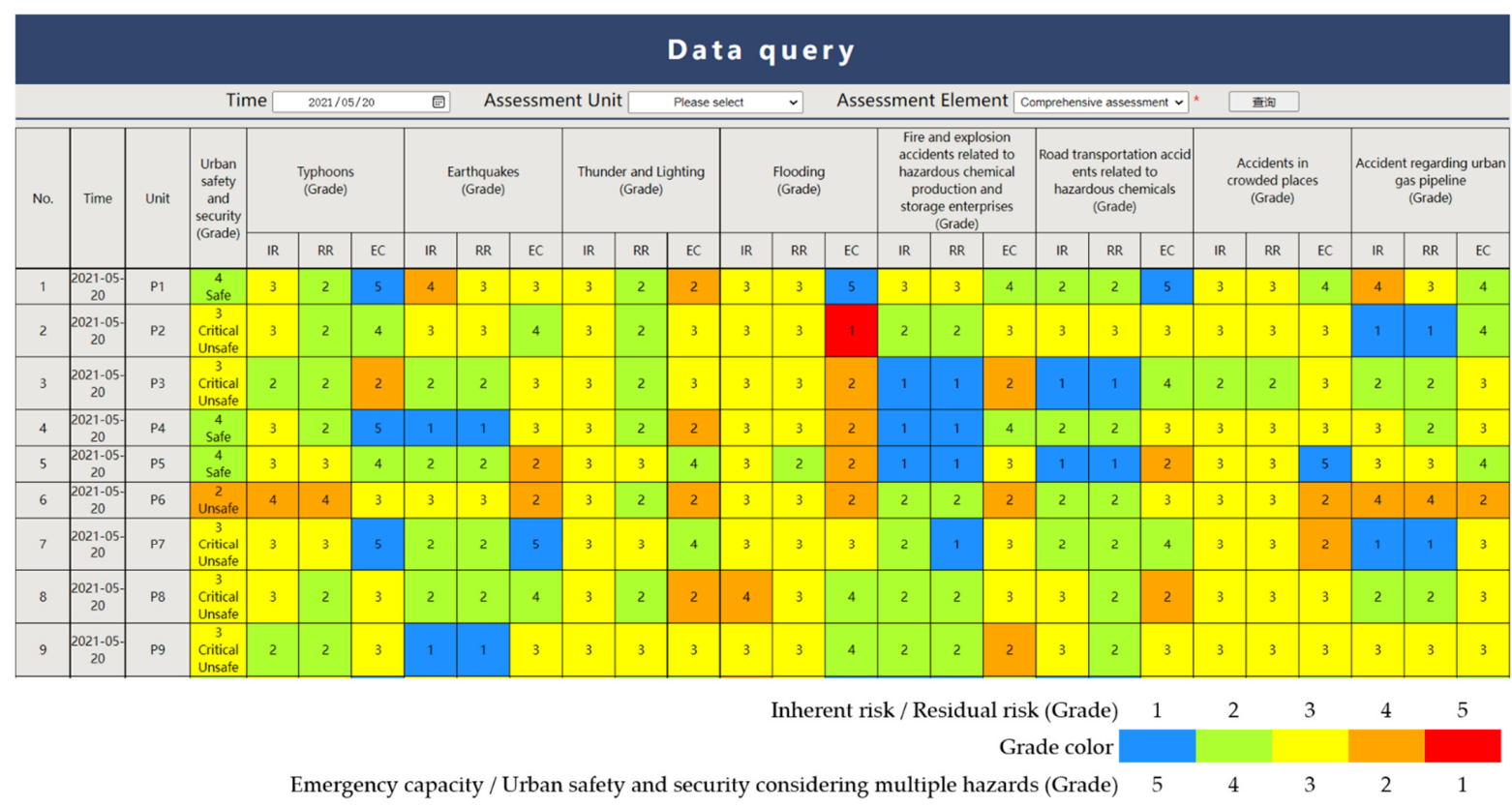

(c)

Figure 7. Front-end interface for each function of the assessment module. (a) Data collection interface; (b) data correction interface; (c) data query interface.

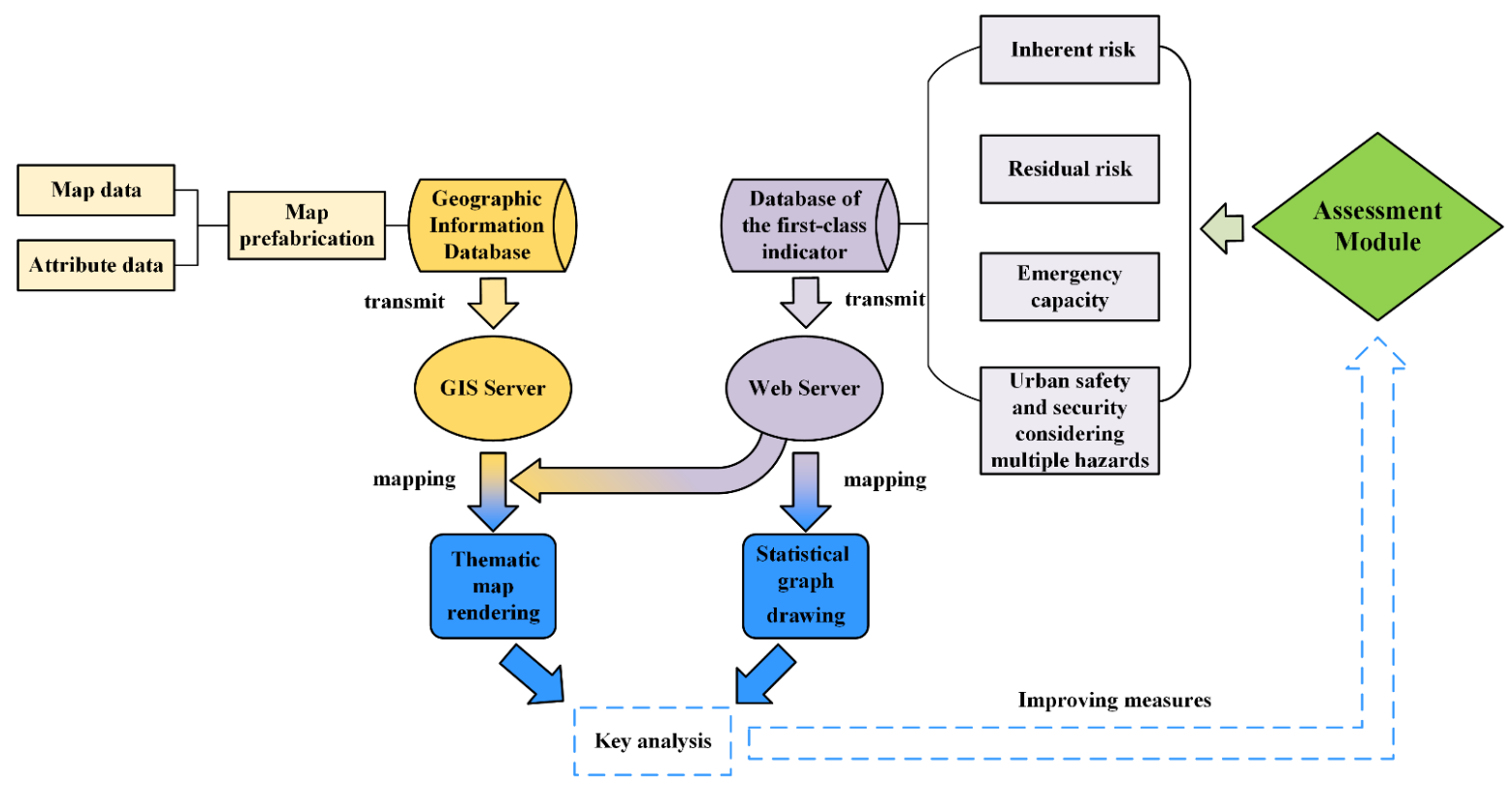

Figure 8. The logic between each function of the visualization module.

\subsubsection{Thematic Map Rendering}

Spatial data are the core requirement of the thematic map rendering function. Collecting and pretreating the visual map data is a necessary process to complete thematic map rendering. The spatial data include map data and attribute data, which are collected according to the data provided by the local administrative department, mainly including the zoning map and the name of the division unit, etc. The pretreating of spatial data involves redrawing and locating the area map data, storing the map data in the geographic information database, and publishing it on the ArcGIS Server. The published map data can be used by the Web server through ArcGIS API for JavaScript. 
Thematic map rendering uses the assessment results of all assessment units through AJAX. According to the different assessment elements, it can employ the assessment grades of inherent risk, residual risk, and emergency capacity for a single-hazard event and the grade of comprehensive urban safety and security considering multiple hazards. Five colors, namely, red, orange, yellow, green, and blue are used as the basic colors of the renderer, so that all units can be colored according to the classification situation corresponding to the assessment results, achieving the visualization effect of a thematic map. This realizes the hierarchical rendering of "single-hazard and single-element" and "multi-hazards and multi-elements" in the assessment area, expanding the visualization level of the results. This function visually presents the spatial distribution of assessment results for single-hazard and multi-hazard events, which is conducive to the independent analysis of single hazards and comprehensive analysis of multiple hazards. The user can formulate corresponding safety-improving measures according to the analysis results, and the data correction after the implementation of measures supports the periodic assessment of the assessment module.

\subsubsection{Statistical Graph Drawing}

The thematic map-rendering function can show the spatial distribution of the assessment results, which is helpful for spatial analysis. However, due to the large number of evaluation units, it is difficult to intuitively observe the statistics of the assessment results only through thematic maps. Therefore, it is necessary to draw a statistical graph to synchronously present the statistical results of the assessment data, which is beneficial for assisting further data analysis and decision-making. The statistical graph drawing function is developed based on the Apache ECharts open-source visualization chart library. The chart library provides a wealth of visual chart types and multiple rendering schemes, supports cross-platform, multi-terminal use, and is a highly integrated and widely used component for statistical graph drawing. While performing thematic map rendering, the assessment results are classified and mapped through the API for ECharts. The statistical numbers and proportions of assessment results grade are obtained through statistical algorithm models, and then they are visualized on the front-end interface in the form of a histogram and pie chart. The front-end interface for each function of the visualization module is shown in Figure 9.

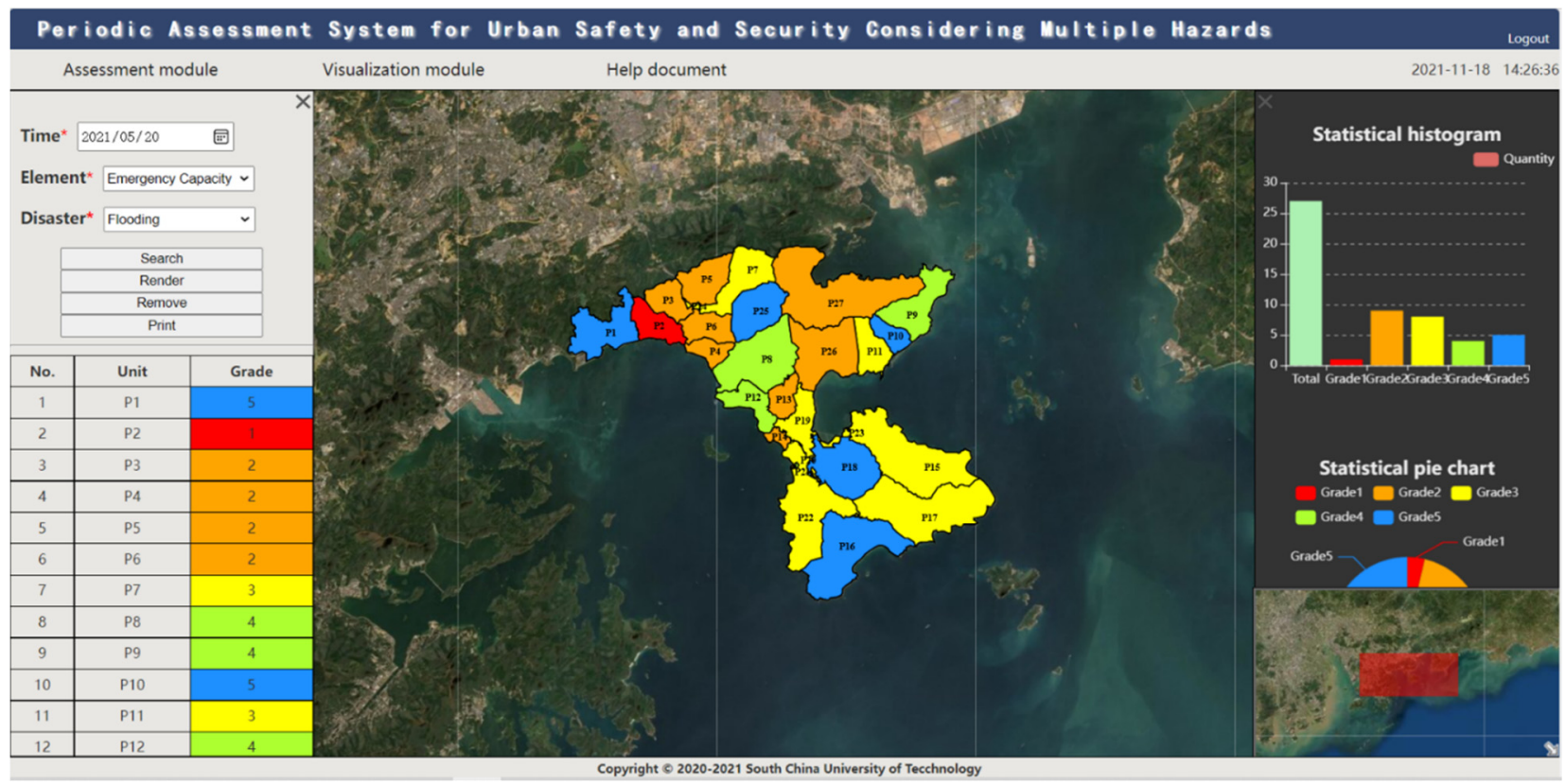

(a)

Figure 9. Cont. 


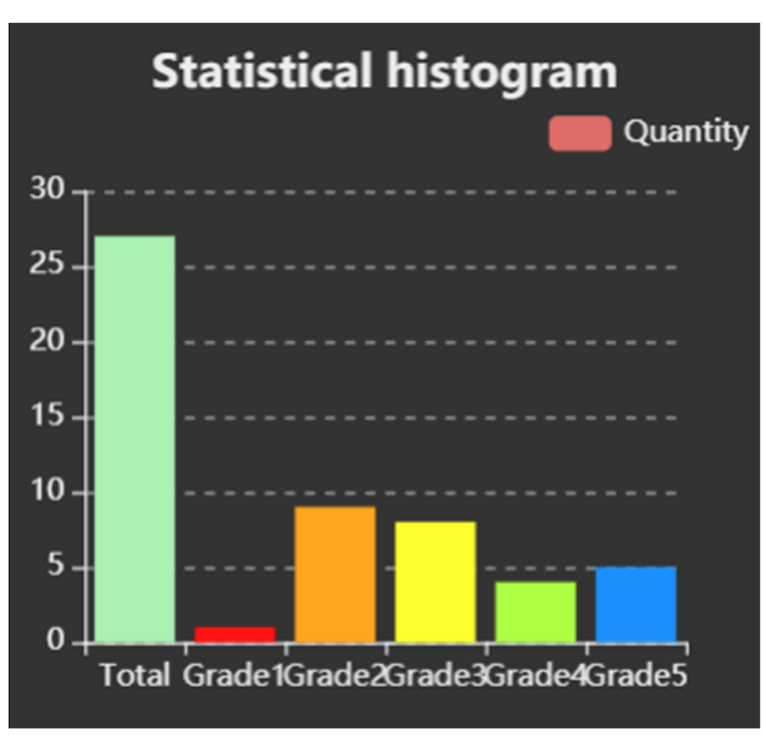

(b)

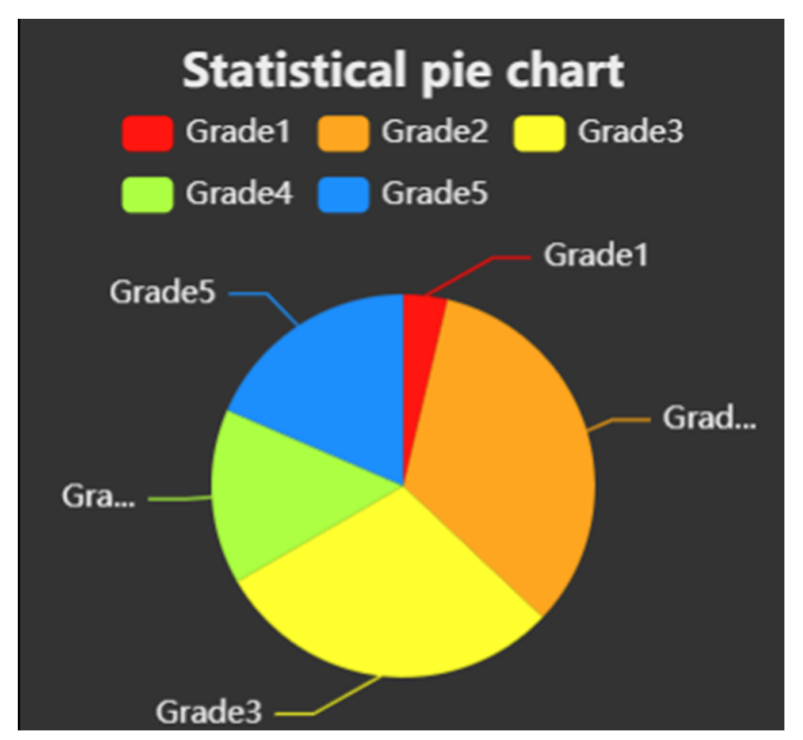

(c)

Figure 9. Front-end interface for each function of the visualization module. (a) Thematic map rendering interface; (b) statistical histogram; (c) statistical pie chart.

\subsection{Assistant Module}

To enhance the user's human-computer interaction experience and provide necessary security protection, the system is equipped with assistant functions, such as user registration and login, and help documents. JSP technology is used to verify whether the input data match the user information in the database, and to add new user information if it needs to register them. Furthermore, specifying the registration serial number provides certain protections for the registration function. The help document provides two means of online browsing and local storage to support users in a rapid-access system operations guide, enhancing the human-computer interaction experience.

\section{Application and Results \\ 4.1. Overview of Application Area}

A typical urban area on the southeast coast of China ("Area P") was taken as an application example of the periodic assessment system for urban safety and security considering multiple hazards. Area $P$ is about $600 \mathrm{~km}^{2}$ in size and is surrounded by sea on three sides, with a coastline that is $128 \mathrm{~km}$ long. Located in the subtropical maritime monsoon climate zone with frequent rainfall, Area P is often hit by typhoons, floods, lightning, and other natural disasters. Meanwhile, the northern region of Area P is adjacent to three seismic belts but the seismic activity is relatively stable. The main industries in Area P are tourism and light industry, including LNG filling stations, oil depots, chemical refineries, etc. There are many kinds and a wide distribution of hazard sources in Area P. Hazardous chemical enterprises, chemical industry parks, and other danger sources are mainly distributed in the middle and northwest of Area P. The transportation route used for hazardous chemicals runs through the middle and north of Area P. In addition, there are many residential areas or crowded places in the north of Area P and some coastal areas, and urban gas pipelines are also distributed within the areas where people gather. Technical accidents can easily occur in areas with concentrated hazard sources. At the height of the tourist season, the population density of the coastal scenic spots in Area P will increase sharply, which has a negative impact on urban safety and security. Because Area $\mathrm{P}$ is affected by a variety of natural disasters and technological accidents, it is suitable for application as a typical urban area. It is divided into 27 communities as assessment units, according to administrative divisions, using the symbols P1-P27 for representation, as shown in Figure 10. 


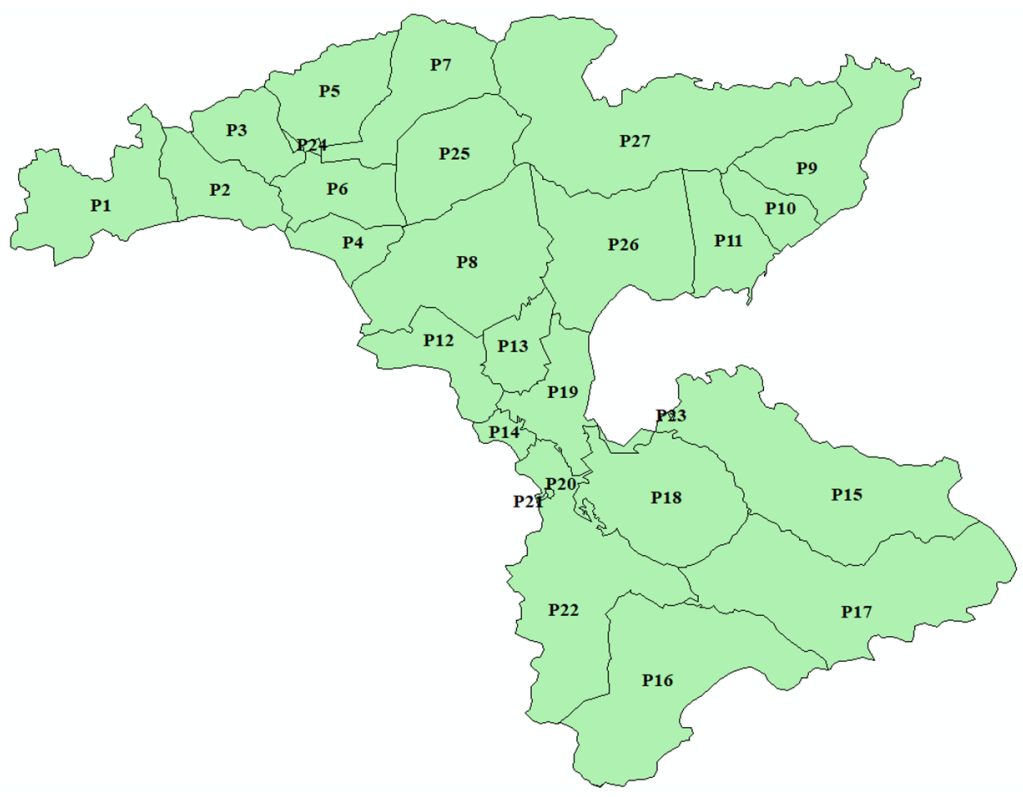

Figure 10. Administrative divisions of Area P.

\subsection{Data Processing and Assessment Results}

According to the characteristics of the location, climate, and urban industry in Area $\mathrm{P}$, we selected eight types of hazard events, such as typhoons, earthquakes, thunder and lightning, flooding, fire and explosion accidents related to hazardous chemical production and storage enterprises, road transportation accidents related to hazardous chemicals, accidents in crowded places, and accidents regarding urban gas pipelines, and conducted an urban safety and security assessment considering multiple hazards for 27 communities in Area P. The code and description of the assessment elements for a single community are shown in Table 1.

Table 1. Assessment elements code and description for a single community.

\begin{tabular}{ll}
\hline Code & \\
\hline gir1 & Inherent risk of typhoons \\
gir2 & Inherent risk of earthquakes \\
gir3 & Inherent risk of thunder and lightning \\
gir4 & Inherent risk of flooding \\
gir5 & Inherent risk of fire and explosion accidents related to hazardous chemical production and storage enterprises \\
gir6 & Inherent risk of road transportation accidents related to hazardous chemicals \\
gir7 & Inherent risk of accidents in crowded places \\
gir8 & Inherent risk of accidents regarding urban gas pipelines \\
\hline grr1 & Residual risk of typhoons \\
grr2 & Residual risk of earthquakes \\
grr3 & Residual risk of thunder and lightning \\
grr4 & Residual risk of flooding \\
grr5 & Residual risk of fire and explosion accidents related to hazardous chemical production and storage enterprises \\
grr6 & Residual risk of road transportation accidents related to hazardous chemicals \\
grr7 & Residual risk of accidents in crowded places \\
grr8 & Residual risk of accidents regarding urban gas pipelines \\
\hline ge1 & Emergency capacity of typhoons \\
ge2 & Emergency capacity of earthquakes \\
ge3 & Emergency capacity of thunder and lightning \\
ge4 & Emergency capacity of flooding \\
ge5 & Emergency capacity of fire and explosion accidents related to hazardous chemical production and storageenterprises \\
ge6 & Emergency capacity of road transportation accidents related to hazardous chemicals \\
ge7 & Emergency capacity of accidents in crowded places \\
ge8 & Emergency capacity of accidents regarding urban gas pipelines \\
\hline gs & Urban safety and security considering multiple hazards \\
\hline
\end{tabular}


As the thirteenth Five-Year Plan for 2016-2020 was formulated in Area P, there was a certain improvement in regional production safety, risk prevention and control, emergency rescue, and so on. In order to better demonstrate the application of our system, we conducted two assessment examples for Area P in 2015 and in 2020. The example assessment information of 2015 and 2020 was based on the geographical conditions, socio-economic conditions, the thirteenth Five-Year Plan of Area P, the previous investigation reports, and the data related to several disaster assessments of the area. Through the sorting and processing of this information, the input parameters of assessment were formed. All the parameters of 27 communities for these two years were input into the system assessment module, with automatic determination of the rating value corresponding to the parameters by means of the configured judgment algorithm. Using the urban safety and security assessment model considering multiple hazards outlined in Section 3.2.2, the system was implemented to calculate the assessment values and grades of the inherent risk, residual risk, and emergency capacity of the eight types of hazard events in each community, as well as the assessment value and grade of the urban safety and security considering multiple hazards in each community. The results for 2015 and 2020 are shown in Tables 2 and 3, respectively.

Table 2. Assessment results of inherent risk, residual risk, emergency capacity, urban safety and security considering multiple hazards in 27 communities in 2015.

\begin{tabular}{|c|c|c|c|c|c|c|c|c|c|c|c|c|c|c|c|c|c|c|c|c|c|c|c|c|c|}
\hline Gra-de & $\underset{\text { ir1 }}{\mathrm{g}}$ & $\underset{\text { ir2 }}{\mathrm{g}}$ & $\underset{\mathrm{ir} 3}{\mathrm{~g}}$ & $\underset{\text { ir4 }}{\mathrm{g}}$ & $\underset{\text { ir5 }}{\mathrm{g}}$ & $\underset{\text { ir6 }}{\mathrm{g}}$ & $\underset{\text { ir7 }}{\mathrm{g}}$ & $\underset{\text { ir8 }}{\mathrm{g}}$ & grr1 & grr2 & grr3 & grr4 & grr5 & grr6 & grr7 & grr8 & ge1 & ge2 & ge3 & ge4 & ge5 & ge6 & ge7 & ge8 & gs \\
\hline P1 & $2^{1}$ & 3 & 2 & 3 & 4 & 5 & 5 & 3 & 2 & 2 & 2 & 3 & 4 & 5 & 5 & 3 & 3 & 3 & 2 & 3 & 4 & 5 & 4 & 4 & 3 \\
\hline P2 & 2 & 3 & 2 & & 3 & 4 & 4 & 3 & 2 & 3 & 2 & & 3 & 4 & 4 & 3 & 2 & 4 & 2 & 2 & 3 & 2 & 3 & 4 & 3 \\
\hline P3 & 2 & 3 & 2 & 3 & 3 & 3 & 5 & 5 & 2 & 3 & 2 & 3 & 2 & 3 & 5 & & 2 & 3 & 2 & 2 & 2 & 2 & 2 & 3 & 2 \\
\hline P4 & 3 & 3 & 3 & 3 & 3 & 4 & 3 & 4 & 2 & 2 & 3 & 3 & 3 & 4 & 3 & 4 & 3 & 3 & 2 & 2 & 3 & 3 & 3 & 3 & 3 \\
\hline P5 & 2 & 3 & 3 & 3 & 4 & 3 & 4 & 4 & 2 & 3 & 3 & 3 & 4 & 3 & 4 & 4 & 4 & 2 & 3 & 2 & 3 & 2 & 3 & 2 & 2 \\
\hline P6 & 2 & 3 & 3 & 4 & 3 & 4 & 4 & 5 & 1 & 3 & 3 & 4 & 3 & 3 & 3 & 4 & 3 & 2 & 2 & 2 & 2 & 3 & 2 & 2 & 2 \\
\hline P7 & 2 & 3 & 3 & 3 & 3 & 3 & 3 & 3 & 2 & 3 & 3 & 3 & 2 & 3 & 3 & 3 & 4 & 3 & 3 & 3 & 3 & 4 & 2 & 3 & 3 \\
\hline P8 & 3 & 3 & 3 & & 2 & 4 & 3 & 4 & 3 & 3 & 2 & 4 & 2 & 4 & 3 & 4 & 3 & 3 & 2 & & 3 & & 3 & 3 & 2 \\
\hline P9 & & 2 & 4 & 3 & 2 & $\begin{array}{l}4 \\
2\end{array}$ & 4 & 2 & & 1 & 4 & 3 & 2 & 2 & 4 & 2 & 3 & 3 & 3 & 3 & 2 & 3 & 3 & 3 & 3 \\
\hline P10 & 5 & 2 & 4 & 4 & 1 & 1 & 4 & 2 & 4 & 2 & 4 & 3 & 1 & 1 & 4 & 2 & 5 & 3 & 3 & 3 & 2 & 3 & 4 & 3 & 3 \\
\hline P11 & 5 & 2 & 4 & 3 & 2 & 2 & 4 & 3 & 5 & 2 & 3 & 3 & 2 & 2 & 4 & 2 & 4 & 3 & 3 & 3 & 1 & 3 & 5 & 4 & 3 \\
\hline P12 & 4 & 1 & 3 & 4 & 3 & 5 & 3 & 5 & 4 & 1 & 3 & 4 & 3 & 4 & 3 & 4 & 4 & 4 & 5 & 4 & 3 & 4 & 3 & 3 & 3 \\
\hline P13 & & 2 & 4 & & 5 & 5 & 4 & 5 & & 2 & 4 & & & 5 & 4 & & & 3 & 1 & & 2 & 2 & 2 & & \\
\hline $\begin{array}{l}\text { P14 } \\
\text { S }\end{array}$ & 4 & 1 & 3 & 5 & 4 & 4 & 3 & 3 & 4 & 1 & 3 & 4 & 4 & 4 & 3 & 3 & 3 & 3 & 3 & 2 & 2 & 4 & 3 & 4 & 3 \\
\hline P15 & & 1 & 3 & 4 & 2 & 3 & 2 & 2 & 4 & 1 & 3 & 4 & 2 & 3 & 2 & 2 & 3 & 4 & 3 & 3 & 3 & 3 & 2 & 3 & 3 \\
\hline P16 & 5 & 1 & 2 & 4 & 2 & 2 & 2 & 1 & 5 & 1 & 2 & 3 & 2 & 2 & 2 & 1 & 5 & 4 & 4 & 5 & 2 & 2 & 4 & 2 & 4 \\
\hline $\begin{array}{l}\text { P17 } \\
\text { S }\end{array}$ & 5 & 1 & 2 & 2 & 1 & 1 & 2 & 1 & 5 & 1 & 1 & 2 & 1 & 1 & 2 & 1 & 4 & 4 & 3 & 3 & 3 & 3 & 2 & 2 & 3 \\
\hline P18 & 3 & 2 & 2 & 2 & 1 & 1 & 3 & 2 & 3 & 2 & 2 & 2 & 1 & 1 & 2 & 1 & 3 & 3 & 3 & 2 & 3 & 2 & 4 & 3 & 4 \\
\hline P19 & 4 & 3 & 3 & 4 & 4 & 3 & 2 & 3 & 3 & 3 & 2 & 4 & 4 & 3 & 2 & 3 & 2 & 3 & 4 & 3 & 2 & 3 & 4 & 5 & 3 \\
\hline P20 & 4 & 3 & 3 & & 3 & 1 & 3 & 3 & 4 & 2 & 3 & 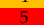 & 2 & 1 & 3 & 3 & 4 & 2 & 2 & 4 & 2 & 2 & 3 & 2 & 3 \\
\hline P21 & 4 & 3 & 2 & 5 & 2 & 2 & 4 & 3 & 4 & 3 & 2 & 4 & 2 & 2 & 4 & 3 & 3 & 3 & 3 & 2 & 2 & 3 & & 4 & 3 \\
\hline P22 & 4 & 2 & 2 & 3 & 1 & 1 & 2 & 1 & 4 & 1 & 2 & 3 & 1 & 1 & 2 & 1 & 3 & 4 & 2 & 3 & 2 & 2 & 3 & 3 & 3 \\
\hline P23 & 5 & 1 & 2 & 3 & 2 & 2 & 2 & 2 & 4 & 1 & 2 & 3 & 2 & 2 & 2 & 2 & 3 & 2 & 3 & 3 & 2 & 4 & 5 & 3 & 3 \\
\hline P24 & 2 & 3 & 2 & 4 & & 4 & & 4 & 2 & 3 & 1 & 4 & & 4 & & 4 & 3 & 2 & 2 & 4 & 2 & 4 & 4 & 2 & 2 \\
\hline P25 & 2 & 3 & 2 & & 5 & 4 & 4 & 4 & 1 & 3 & 2 & & 4 & 4 & 4 & 3 & 3 & 2 & 3 & 5 & 4 & 4 & 2 & 2 & 3 \\
\hline P26 & 4 & 3 & 4 & 4 & 3 & 2 & 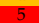 & 3 & 4 & 3 & 4 & 3 & 3 & 2 & & 3 & 4 & 3 & 3 & 2 & 3 & 2 & 4 & 2 & 3 \\
\hline P27 & 4 & 3 & 3 & 3 & 3 & 2 & 2 & 1 & 3 & 3 & 3 & 3 & 3 & 1 & 2 & 1 & 2 & & 3 & 2 & 2 & 3 & 2 & 3 & 2 \\
\hline
\end{tabular}

${ }^{1}$ Using (blue), (green), (yellow), (orange), and $\quad$ (red) to represent the first to fifth grades of inherent risk and residual risk, while using (red), (orange), (yellow), (green), and (blue) to represent the first to fifth grades of emergency capacity and urban safety and security considering multiple hazards.

\subsection{Visualization of the Assessment Result}

Corresponding to the assessment results shown in Tables 2 and 3, the visualization module of the system was used to render each assessment element. According to the impact of assessment elements on urban safety and security, the higher the grade of inherent risk and residual risk, the greater the threat to urban safety and security. Therefore, we use blue, green, yellow, orange, and red to represent the first to fifth grades of inherent risk and residual risk, respectively. Conversely, the higher the grade of emergency capacity, the smaller the threat to urban safety and security, and the higher the grade of urban safety and security considering multi-hazards, the safer the urban area, so we used red, orange, yellow, green, and blue, respectively, to represent the first to fifth grades of emergency capacity and urban safety and security considering multiple hazards. Using the ArcGIS map resource of Area P for rendering, the hierarchical distribution of each assessment element can be intuitively observed. Taking the assessment result of urban safety and security considering multiple hazards (gs) as an example, the rendering effect of the hierarchical map for 2015 and 2020 is shown in Figure 11. 
Table 3. Assessment results of inherent risk, residual risk, emergency capacity, urban safety and security considering multiple hazards in 27 communities in 2020.

\begin{tabular}{|c|c|c|c|c|c|c|c|c|c|c|c|c|c|c|c|c|c|c|c|c|c|c|c|c|c|}
\hline Gra-de & $\underset{\text { ir1 }}{\mathrm{g}}$ & $\begin{array}{l}\mathrm{g} \\
\text { ir2 }\end{array}$ & $\begin{array}{c}\mathrm{g} \\
\mathrm{ir} 3 \\
\end{array}$ & $\begin{array}{c}\mathrm{g} \\
\text { ir4 }\end{array}$ & $\underset{\mathrm{ir} 5}{\mathrm{~g}}$ & $\underset{\text { ir6 }}{\mathrm{g}}$ & $\underset{\text { ir7 }}{\mathrm{g}}$ & $\underset{\text { ir8 }}{\mathrm{g}}$ & grr1 & grr2 & grr3 & grr4 & grr5 & grr6 & grr7 & grr8 & ge1 & ge2 & ge3 & ge4 & ge5 & ge6 & ge7 & ge8 & gs \\
\hline P1 & $3^{1}$ & 3 & 2 & 3 & 4 & 5 & 5 & 4 & 2 & 2 & 2 & 3 & 3 & 4 & 4 & 3 & 5 & 3 & 2 & 5 & 4 & 5 & 4 & 4 & 4 \\
\hline P2 & 3 & 3 & 2 & 5 & 4 & 4 & 5 & 4 & 2 & 3 & 2 & 3 & 2 & 3 & 4 & 3 & 4 & 4 & 3 & 2 & 3 & 3 & 3 & 4 & 3 \\
\hline P3 & 2 & 3 & 2 & 3 & 3 & 3 & 5 & 5 & 2 & 3 & 2 & 3 & 1 & 2 & 4 & 4 & 2 & 3 & 3 & 2 & 2 & 3 & 3 & 3 & 3 \\
\hline P4 & 3 & 3 & 2 & 3 & 4 & 4 & 4 & 5 & 2 & 2 & 2 & 3 & 3 & 2 & 3 & 3 & 5 & 3 & 2 & 2 & 4 & 3 & 3 & 4 & 4 \\
\hline P5 & 3 & 3 & 3 & 3 & 4 & 4 & & 4 & 2 & 2 & 3 & 2 & 3 & 2 & 3 & 3 & 4 & 2 & 4 & 2 & 3 & 2 & 5 & 4 & 4 \\
\hline P6 & 2 & 3 & 3 & 4 & 3 & 3 & 5 & 5 & 1 & 3 & 2 & 3 & 2 & 3 & 5 & 4 & 3 & 2 & 2 & 2 & 2 & 3 & 2 & 2 & 2 \\
\hline P7 & 2 & 3 & 3 & 3 & 3 & 3 & 3 & 4 & 2 & 3 & 3 & 3 & 2 & 2 & 3 & 3 & 5 & 3 & 4 & 3 & 3 & 4 & 2 & 3 & 3 \\
\hline P8 & 3 & 3 & 3 & 5 & 2 & 4 & 3 & 4 & 2 & 3 & 2 & 3 & 2 & 3 & 3 & 3 & 3 & 4 & 2 & 4 & 3 & 2 & 3 & 3 & 3 \\
\hline P9 & & 2 & 4 & 3 & 2 & 2 & 4 & 2 & 4 & 1 & 3 & 3 & 2 & 2 & 3 & 2 & 3 & 3 & 3 & 4 & 2 & 3 & 3 & 3 & 3 \\
\hline P10 & 5 & 2 & 4 & & 1 & 2 & 5 & 2 & 3 & 2 & 2 & 3 & 1 & 1 & 3 & 2 & 5 & 3 & 4 & 5 & 2 & 3 & 4 & 4 & 4 \\
\hline P11 & 5 & 2 & 4 & 3 & 2 & 2 & 5 & 3 & 4 & 2 & 3 & 3 & 2 & 2 & 4 & 2 & 4 & 4 & 3 & 3 & 3 & 3 & 5 & 4 & 3 \\
\hline P12 & 4 & 1 & 3 & 4 & 4 & 5 & 4 & 5 & 2 & 1 & 3 & 3 & 3 & 4 & 3 & 4 & 4 & 4 & 5 & 4 & 4 & 4 & 3 & 4 & 4 \\
\hline P13 & 5 & 2 & 4 & 5 & 5 & 5 & 4 & 5 & 5 & 2 & 4 & 4 & 4 & 5 & 4 & 4 & 2 & 3 & 1 & 2 & 2 & 2 & 2 & & \\
\hline P14 & 4 & 2 & 3 & 5 & 4 & 4 & 4 & 3 & 3 & 1 & 2 & 4 & 3 & 2 & 3 & 2 & 3 & 4 & 3 & 2 & 3 & 4 & 4 & 4 & 4 \\
\hline P15 & & 2 & 3 & 4 & 2 & 4 & 2 & 2 & 3 & 1 & 2 & 3 & 1 & 2 & 2 & 2 & 4 & 4 & 5 & 3 & 3 & 4 & 3 & 3 & 4 \\
\hline P16 & 4 & 1 & 2 & 4 & 2 & 2 & 2 & 2 & 2 & 1 & 1 & 2 & 2 & 2 & 2 & 1 & 5 & 5 & 5 & 5 & 2 & 3 & 5 & 2 & 5 \\
\hline P17 & 5 & 1 & 2 & 2 & 1 & 2 & 2 & 2 & 3 & 1 & 1 & 2 & 1 & 1 & 2 & 1 & 4 & 4 & 4 & 3 & 3 & 4 & 2 & 2 & 4 \\
\hline P18 & 3 & 2 & 2 & 2 & 1 & 1 & 3 & 2 & 2 & 1 & 2 & 2 & 1 & 1 & 2 & 1 & 5 & 5 & 4 & 5 & 3 & 2 & 5 & 4 & 5 \\
\hline P19 & 4 & 3 & 3 & 4 & 4 & 3 & 2 & 3 & 3 & 3 & 2 & 3 & 3 & 3 & 2 & 3 & 2 & 4 & 4 & 3 & 3 & 3 & 4 & 5 & 3 \\
\hline P20 & 4 & 3 & 3 & 4 & 3 & 1 & 3 & 3 & 3 & 2 & 2 & 3 & 2 & 1 & 3 & 3 & 4 & 2 & 3 & 4 & 2 & 2 & 4 & 3 & 3 \\
\hline P21 & 4 & 3 & 2 & 5 & 2 & 2 & 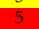 & 3 & 3 & 3 & 2 & 3 & 2 & 2 & 3 & 2 & 3 & 3 & 3 & 3 & 2 & 3 & 2 & 4 & 3 \\
\hline P22 & 4 & 2 & 2 & 3 & 1 & 1 & 2 & 2 & 3 & 1 & 2 & 3 & 1 & 1 & 2 & 1 & 5 & 4 & 3 & 3 & 2 & 2 & 3 & 4 & 4 \\
\hline $\mathrm{P} 23$ & & 1 & 2 & 3 & 2 & 2 & 3 & 2 & 3 & 1 & 2 & 3 & 2 & 2 & 2 & 2 & 3 & 2 & 3 & 3 & 2 & 4 & 5 & 4 & 4 \\
\hline P24 & 2 & 3 & 3 & 4 & 4 & 5 & 5 & 4 & 2 & 2 & 1 & 2 & 4 & 4 & 3 & 3 & 3 & 3 & 2 & 4 & 2 & 4 & 4 & 4 & 4 \\
\hline P25 & 2 & 3 & 2 & 4 & & 4 & 5 & 4 & 2 & 3 & 2 & 3 & 3 & 3 & 4 & 3 & 3 & 2 & 4 & 5 & 4 & 4 & 2 & 3 & 3 \\
\hline P26 & 4 & 3 & 4 & 4 & 3 & 2 & 4 & 4 & 3 & 3 & 3 & 3 & 2 & 2 & 4 & 3 & 4 & 5 & 3 & 4 & 3 & 4 & 4 & 4 & 4 \\
\hline P27 & 4 & 3 & 4 & 3 & 2 & 3 & 2 & 3 & 3 & 3 & 3 & 3 & 1 & 3 & 1 & 2 & 2 & 1 & 2 & 2 & 3 & 2 & 3 & 3 & 2 \\
\hline
\end{tabular}

${ }^{1}$ Using (blue), (green), (yellow), (orange), and $\quad$ (red) to represent the first to fifth grades of inherent risk and residual risk, while using (red), (orange), (yellow), (green), and (blue) to represent the first to fifth grades of emergency capacity and urban safety and security considering multiple hazards.

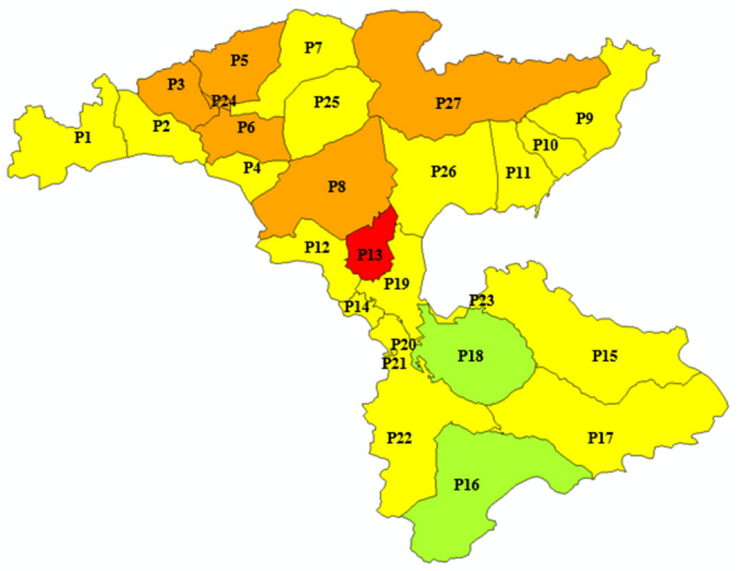

(a)

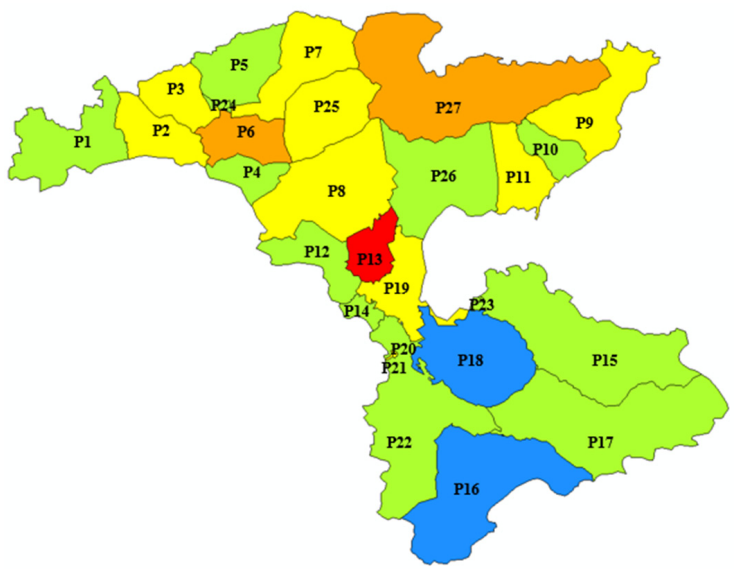

(b)

Figure 11. Thematic map of urban safety and security considering multiple hazards in Area P. (a) In 2015; (b) in 2020.

\section{Discussion}

According to the example assessment results of Area P in 2015 and 2020, obtained following the steps in Section 4, the inherent risks, residual risks, and emergency capacity of eight types of hazard events are analyzed in depth. This study also performs a comprehensive analysis of urban safety and security considering multiple hazards, and conducts an overall discussion on the safety and security level of Area P. In the following figure, the bar chart represents the inherent risk, the line chart represents the residual risk, and the area chart represents the emergency capacity.

Figure 12 shows the comparative analysis results for typhoons. In terms of inherent risk, there is no significant change in the assessment results for 2015 and 2020, and the high-risk areas are mainly located in communities P9 to P23. According to the survey data, these communities, located in the coastal area in the southeast of Area P, are more vulnerable to typhoon disasters. Therefore, the inherent risk value is generally high. The change in typhoon meteorological data in 2015 and 2020 is not obvious, so the results have not changed greatly. In terms of residual risk, the assessment results in 2020 are generally lower than those in 2015, indicating that Area P has improved its prevention and control measures for typhoon disasters. Especially in high-risk communities, the improvement 
effect of prevention and control is more obvious. In terms of emergency capacity, the assessment results in 2020 are generally higher than those in 2015, indicating that Area P has generally improved the emergency capacity of typhoon disasters, but the results for some communities, such as P3, P13, P19, and P27, are still low. The P13 community should receive more attention, due to the high residual risk and low emergency capacity.

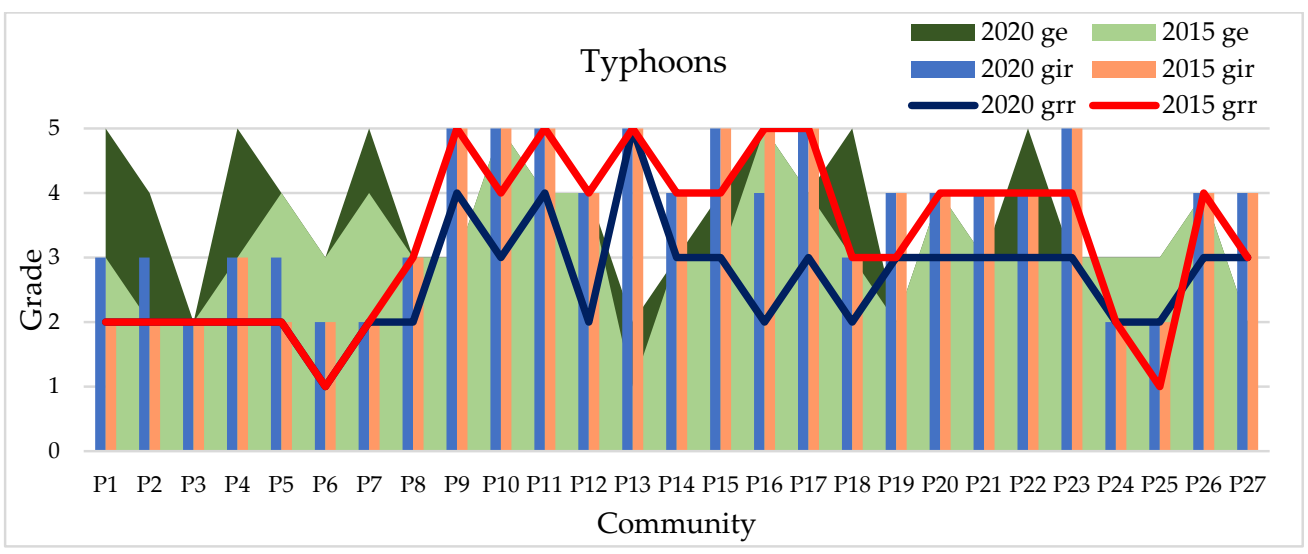

Figure 12. The comparative analysis results for typhoons in 2015 and 2020.

Figure 13 shows the comparative analysis results for earthquakes. In terms of inherent risk, the results for the two studied years are relatively close, with a low level, and the communities with relatively high risks are P1-P8, P19-P20, and P24-P27. According to the survey data, these communities are located in the northwest area. Since there are three seismic belts in the north of Area $\mathrm{P}$, the seismic risk in the northwest is slightly higher. However, due to the stable activity of the seismic belts, the risk in this region is relatively low. In terms of residual risk, the results for the two years are basically the same, indicating that the prevention and control capacity of earthquakes has not effectively improved. In terms of emergency capacity, the level of all communities is generally high, which had improved to a certain extent by 2020 compared with 2015. The communities with improved capacity are mainly low-risk communities, while the improvement range of high-risk communities is not as high.

Figure 14 shows the comparative analysis results for thunder and lightning. In terms of inherent risk, the results for the two years are relatively close, and the high-risk areas are mainly located in the P9-P13 and P26-P27 communities. The survey data show that these communities are mainly located in the middle and northeast of Area P, where lightning occurs intensively. These areas are affected by thunder and lightning more times per year than other regions, and there are many residential areas and some industrial parks, so the risk of harm is greater. In terms of residual risk, the results in 2020 are generally lower than those in 2015, and the decline is more obvious for areas with high risk, indicating that the prevention and control capacity of thunder and lightning has been effectively improved. In terms of emergency capacity, the results are generally high, which had improved to a certain extent by 2020. However, the capacity of some communities is still low. Among them, P13 should receive attention, due to its high residual risk and low emergency capacity.

Figure 15 shows the comparative analysis results for flooding. In terms of inherent risk, the results for the two studied years are almost unchanged. There are many highrisk communities with scattered distribution, which are concentrated in the northwest, middle, and south. According to the survey data, such areas are relatively low-lying and vulnerable to floods. In terms of residual risk, the results in 2020 are lower than those in 2015, indicating that the flood prevention and control capacity has been improved, and the improvement effect is more obvious for high-risk areas. In terms of emergency capacity, this demonstrated a certain improvement by 2020. The capacity of some high-risk communities (P8, P10, and P25) has improved significantly, but that of the other high-risk communities 
(P2-P6, P13-P14, P27) is still at a low level. The focus should be placed on improvements for $\mathrm{P} 13$ and $\mathrm{P} 14$ in particular.

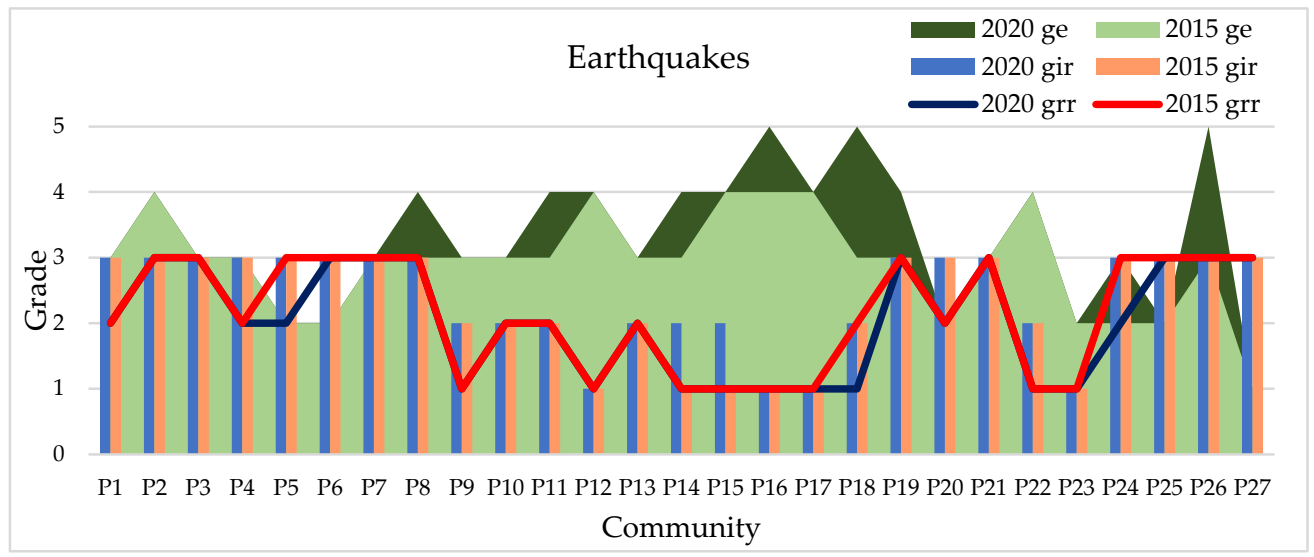

Figure 13. The comparative analysis results for earthquakes in 2015 and 2020.

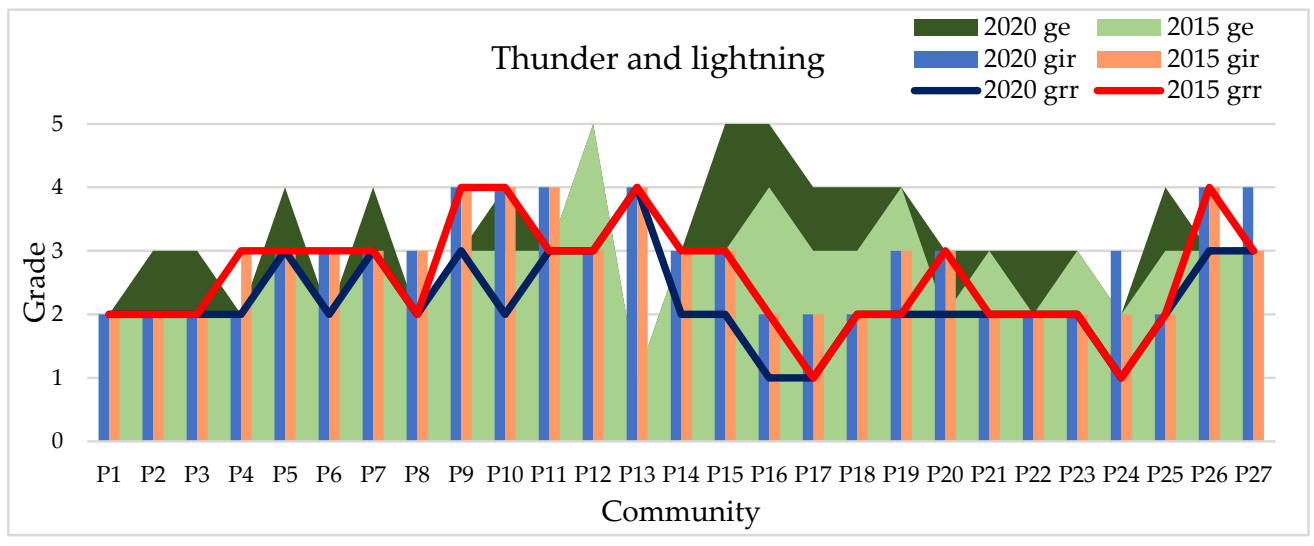

Figure 14. The comparative analysis results for thunder and lightning in 2015 and 2020.

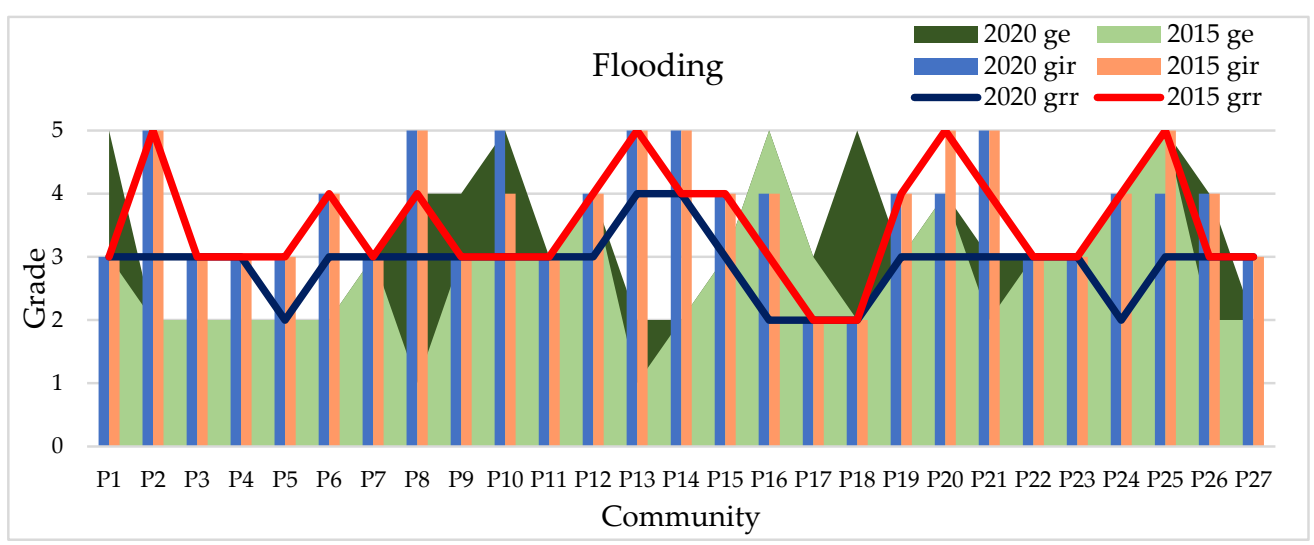

Figure 15. The comparative analysis results for flooding in 2015 and 2020.

Figure 16 shows the comparative analysis results for fire and explosion accidents related to hazardous chemical production and storage enterprises. In terms of inherent risk, that of some communities had increased by 2020. The main high-risk communities are P1-P2, P4-P5, P12-P14, P19, and P24-P25. The survey data show that such communities are distributed in the northwest and middle part, which is similar to the geographical distribution of the industrial park, and so the inherent risk in these areas is high. In terms of residual risk, the results in 2020 are generally lower than those in 2015, especially in highrisk communities, indicating that the prevention and control capacity of such a disaster 
has been improved. In terms of emergency capacity, although that in 2020 is better than that in 2015, the results are generally low. The capacity of some high-risk communities can be adapted, but that of some others, such as P13 and P24, is still low and needs to be improved.

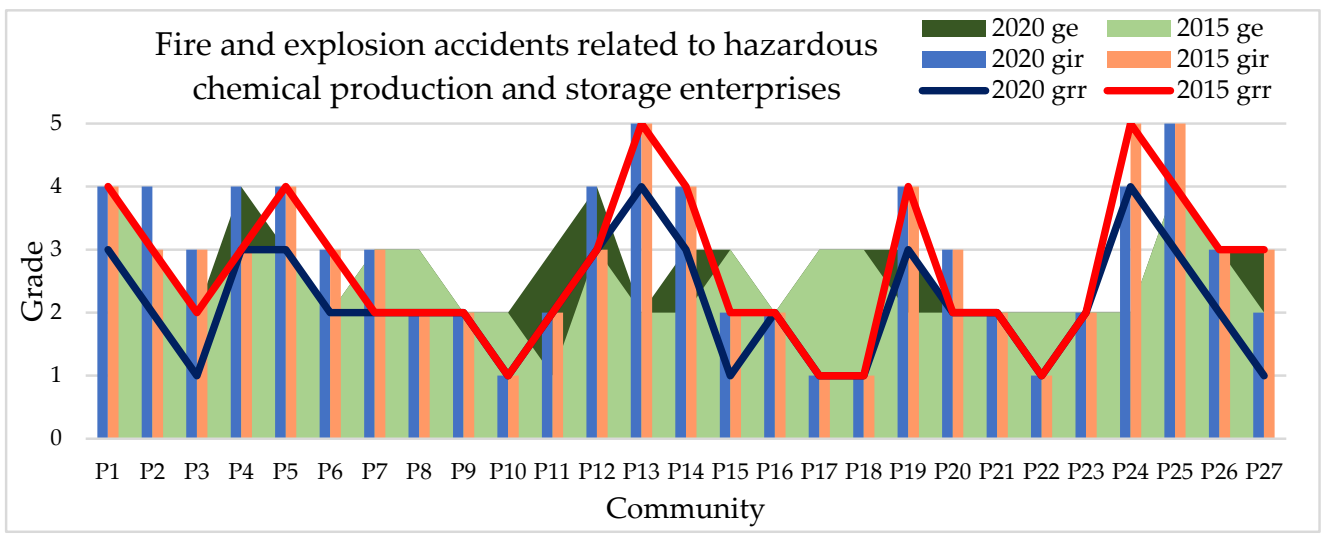

Figure 16. The comparative analysis results for fire and explosion accidents related to hazardous chemical production and storage enterprises in 2015 and 2020.

Figure 17 shows the comparative analysis results for road transportation accidents related to hazardous chemicals. In terms of inherent risk, that of a small number of communities increased; the main high-risk communities are P1-P2, P4-P5, P8, P12-P15, and P24-P25. According to the survey data, these communities are located in the northwest and middle of Area P. As there are many industrial parks in these areas, the transportation routes of hazardous chemicals are numerous. The chemicals are mainly transported to other cities via these routes in the northwest of Area P; thus, the inherent risk in this area is also high. In terms of residual risk, the results of high-risk communities in 2020 are lower than those in 2015, but there are no significant changes in low-risk communities, indicating that the prevention and control capacity for high-risk communities has been emphatically improved, while the promotion effect of P12, P13, and P24 is not obvious. In terms of emergency capacity, the capacity for such a hazard has been improved, but the capacity of some communities, such as P8 and P13, does not match their high risk.

Figure 18 shows the comparative analysis results for accidents in crowded places. In terms of inherent risk, the results in 2020 are generally higher than those in 2015. The main high-risk communities are P1-P6, P9-P14, P21, and P24-P26. The survey data show that such communities are mainly distributed in the north. As industrial parks, urban residential areas, and some coastal scenic spots are distributed in the northwest, northeast, and central areas of Area P, there are many crowded places. Moreover, given the region's economic development, the population in Area P is increasing, and the number of crowded places is increasing year on year. Therefore, the risk is also increasing accordingly. In terms of residual risk, the results in 2020 are generally lower, indicating that the prevention and control capacity of this hazard has been improved, but that of a certain community (P6) has also been weakened. In terms of emergency capacity, the overall results are high, and improved by 2020. However, the capacity of some high-risk communities such as P2, P3, P6, P13, P21, and P25 is still low and needs to be improved.

Figure 19 shows the comparative analysis results for accidents regarding urban gas pipelines. In terms of inherent risk, the results in 2020 are higher than those in 2015, and the main high-risk communities are P1-P8, P12-P13, and P24-P26. According to the survey data, such communities are mainly distributed in the northwest and middle of Area P. Due to the dense distribution of urban gas pipelines, the inherent risk in these areas is also high. The risk distribution is not completely consistent with crowded places, which may be caused by the few gas pipelines in the northeast coastal area and the use of bottled gas in some areas. In terms of residual risk, the results in 2020 are generally lower, mainly due to the decline in some high-risk areas, indicating that Area P has improved the prevention and 
control capacity of this hazard for high-risk communities. In terms of emergency capacity, there is a certain improvement by 2020, but the capacity of some high-risk communities, such as P6 and P13, is still low and needs to be continuously improved.

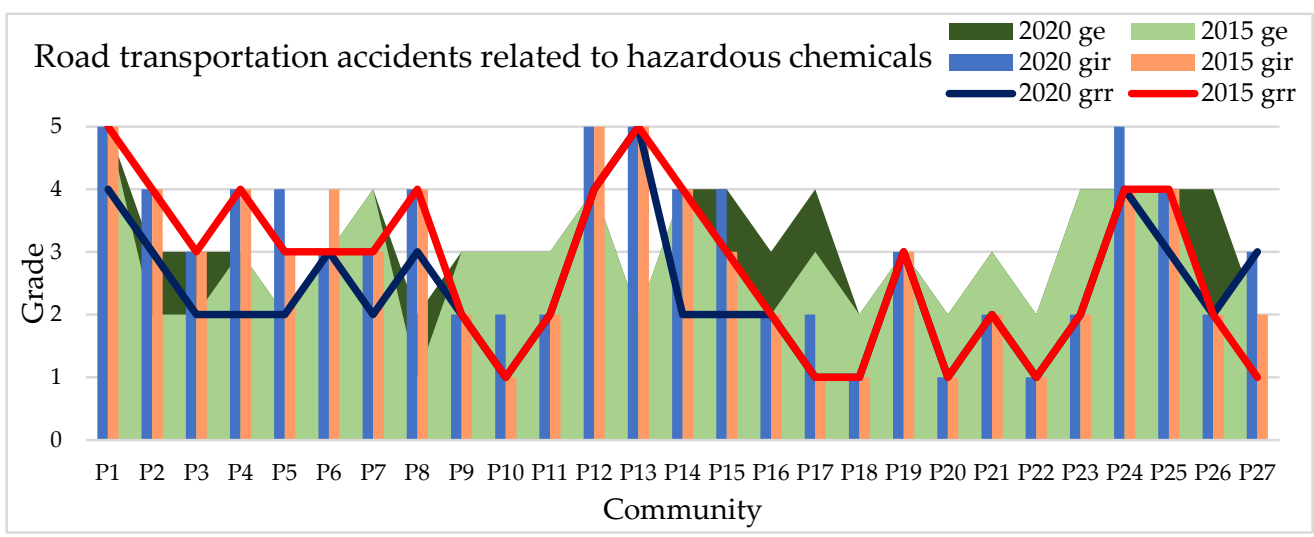

Figure 17. The comparative analysis results for road transportation accidents related to hazardous chemicals in 2015 and 2020.

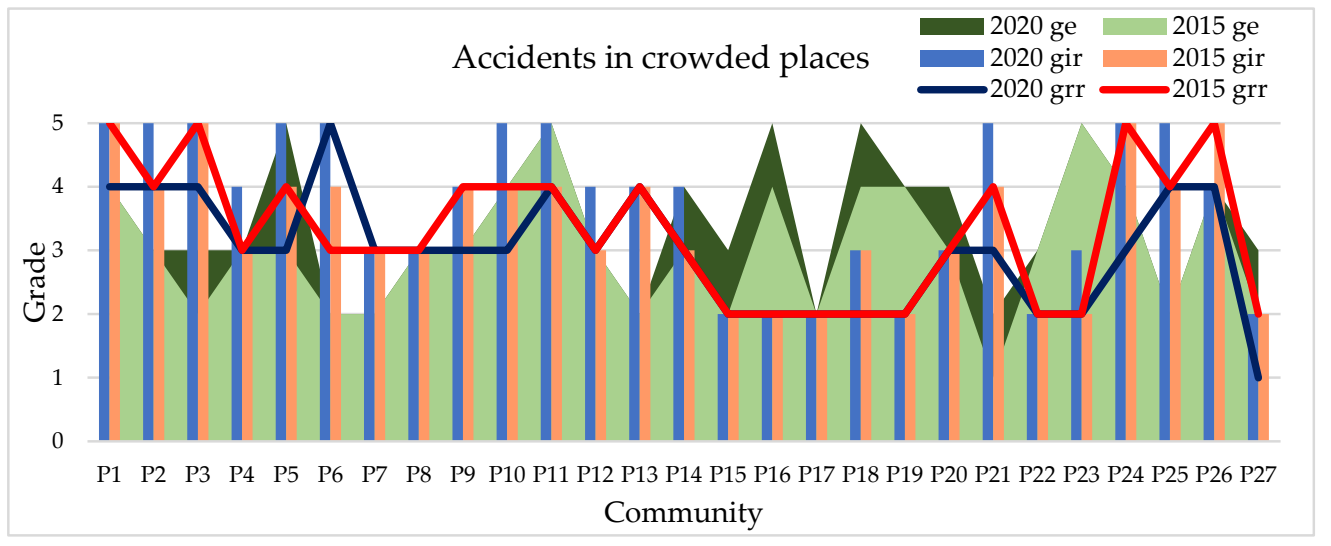

Figure 18. The comparative analysis results for accidents in crowded places in 2015 and 2020.

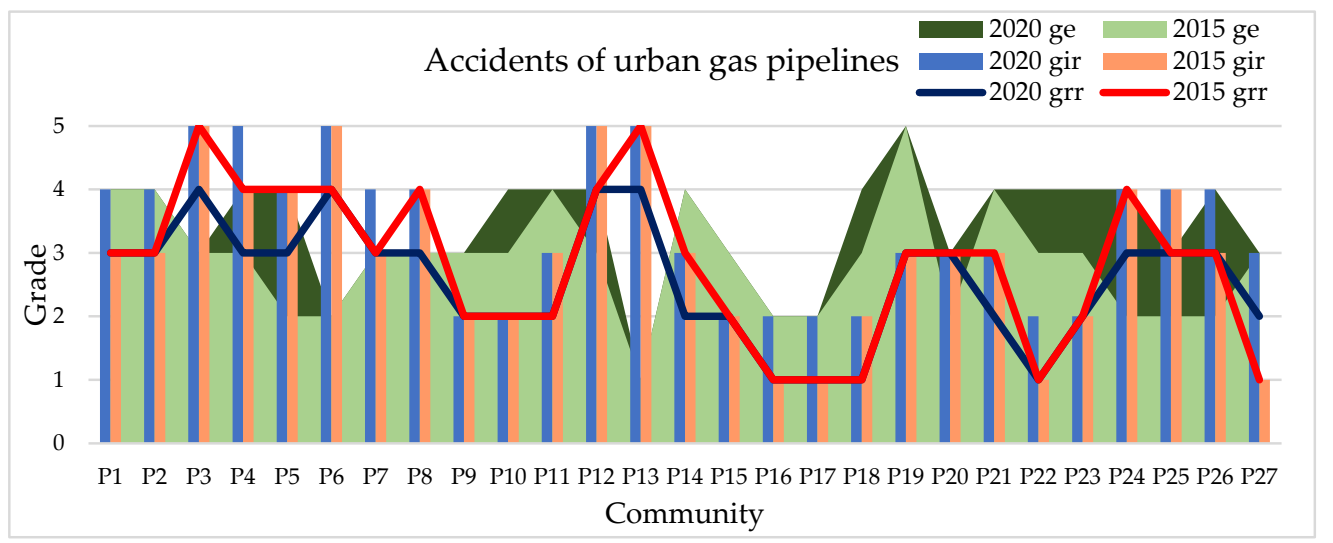

Figure 19. The comparative analysis results for accidents regarding urban gas pipelines in 2015 and 2020.

Combined with Figures 11 and 20, the assessment results of urban safety and security considering multiple hazards, in 2015 and 2020 are compared and analyzed. The safety and security level is generally higher than that in 2015. Among the 27 communities, the proportion of communities in a critical safety state and above (i.e., the assessment value 
is greater than or equal to 3) increased from $74 \%$ in 2015 to $89 \%$ in 2020 . This shows that the thirteenth Five-Year Plan, once implemented, has had a positive impact on the overall urban safety and security of Area P. However, there are still communities with low safety and security levels, which are mainly distributed in the middle and north of Area P. For example, P13 is in a most unsafe state, while P6 and P27 are also in an unsafe state. P13 is located in the middle of Area P. Due to its coastal location, concentrated hazard sources and dense population, the inherent risk of each hazard event in the community is very high. In addition, the field survey reflects the imperfect emergency management and emergency facilities in this community, which is the reason for the insufficient emergency capacity. It is difficult to match many types of high-risk hazards, resulting in the most unsafe state of the community. P6 and P27 are located in the north of Area P's urban area. There is a situation of high risk and insufficient emergency capacity for many hazard events as well, which leads to the unsafe state of the community. For those communities with a low safety and security level, it is necessary to continuously improve the prevention and control capacity and emergency capacity for high-risk hazards in the community, to reduce the impact of single-category hazards and to improve the overall urban safety and security. The revised data after the implementation of the improvement measures can be provided for assessment in the next period. Overall, the assessment results in 2015 and 2020 are basically consistent with the risk and capacity information obtained from the investigation, which indicates that the assessment system is useful and the assessment results are effective.

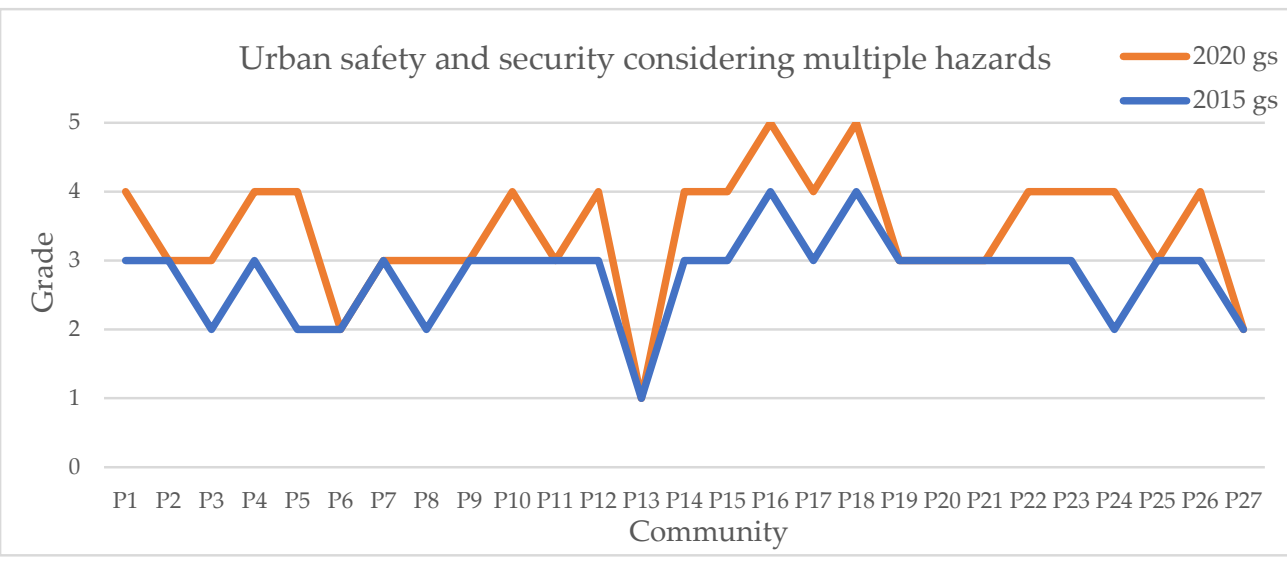

Figure 20. The comparative analysis results for urban safety and security considering multiple hazards in 2015 and 2020.

\section{Conclusions}

This paper presents a periodic assessment system for urban safety and security considering multiple hazards, based on WebGIS. Taking the B/S structure as the system architecture and taking the Struts MVC mode as the development mode, combined with the assessment's theoretical structure based on risk and capability, the framework of the system is built. Using programming techniques such as Java, HTML, CSS, and JavaScript, etc., we designed and implemented three functional modules, including an assessment module, visualization module, and assistant module. The assessment module highly integrates the urban safety and security assessment model considering multiple hazards that the authors have studied, and realizes the rapid calculation and periodic assessment of data. The visualization module renders the thematic map hierarchically, intuitively presenting the spatial distribution and statistics of results for single-hazard and multihazard assessment elements. The assistant module enhances the system security and human-computer interaction experience. The assessment system has been applied to Area $\mathrm{P}$ along the southeastern coast of China, to obtain a thematic map of urban safety and security considering multiple hazards. From the aspects of inherent risk, residual risk, and emergency capacity related to eight types of hazard events, as well as the comprehensive 
urban safety and security of multiple hazard events, we compare the changes in safety and security level from 2015 to 2020, analyze the causes of the changes in combination with the investigation, and assist in decision-making. The given examples can guide future case applications and indicate the effectiveness of the assessment results.

The development and application results show that the periodic assessment system for urban safety and security considering multiple hazards presented in this study can collect and calculate data comprehensively and efficiently, taking into account the combined effects of multiple hazard events, and can obtain an effective assessment result. It can visualize the grades of urban safety and security considering multiple hazards in the assessment area, reflecting spatial distribution and statistics intuitively and clearly. Through the key analysis of the visual assessment results, the decision to implement improvement measures can be assisted, and the corrected data after implementation can support the periodic assessment. The system can be extended and applied to different levels of urban areas, which is convenient for grid-based management and periodic assessment, with high promotion and application value. However, the system still has its limitations. For example, the assessment data mainly depend on manual input, and the real-time automatic updating of data has not been realized; the assessment results are used to assist decisionmaking but fail to provide direct decision support; the developed system is applicable at the community level but the classification standards need to be adjusted when applied to urban areas at different levels. Therefore, in future research, the following aspects can be improved: (1) optimizing the assessment model and grading standard; (2) using the Internet of Things or other data interfaces to monitor and collect quantitative data in real-time; and (3) providing dynamic decision information intelligently according to the assessment results of single and multiple hazards.

Author Contributions: X.C. developed the assessment system and its application, analyzed the results, drafted the manuscript, and finalized it; G.C. administrated and supervised this study, acquired funding and data, and provided suggestions on the manuscript; Q.Y. provided support for the assessment model; J.L. contributed to manuscript writing and proofreading. Z.Y. and S.J. provided suggestions on this study. All authors have read and agreed to the published version of the manuscript.

Funding: This study was supported by the Science and Technology Planning Project of Guangdong Province, China (2019B020208011), and the Science and Technology Planning Project of Guangzhou (201903010102).

Institutional Review Board Statement: Not applicable.

Informed Consent Statement: Not applicable.

Data Availability Statement: The data presented in this study are available on request from the corresponding author. The data are not publicly available due to confidentiality.

Acknowledgments: Acknowledgment is due to the local authorities and expert groups of Area P, as well as to all contributors.

Conflicts of Interest: The authors declare no conflict of interest.

\section{References}

1. United Nations Department of Economic and Social Affairs. World Urbanization Prospects The 2018 Revision. 2019. Available online: https:/ / population.un.org/wup/Publications/Files/WUP2018-Report.pdf (accessed on 1 May 2021).

2. Wang, J.; Weng, W. Discrimination on concept of multi-hazard and review of research on relationship between disasters and accidents. J. Saf. Sci. Technol. 2019, 15, 57-64.

3. Ghosh, A.; Kar, S.K. Application of analytical hierarchy process (AHP) for flood risk assessment: A case study in Malda district of West Bengal, India. Nat. Hazards 2018, 94, 349-368. [CrossRef]

4. Kim, J.; Son, K.; Yum, S.; Ahn, S. Typhoon Vulnerability Analysis in South Korea Utilizing Damage Record of Typhoon Maemi. Adv. Civ. Eng. 2020, 2020, 8885916. [CrossRef]

5. Lin, A.; Zhang, M. Risk assessment of mountain torrents in mountain scenic spots of Fujian Province. J. Jilin Norm Univ. Nat. Sci. Ed. 2020, 41, 132-140. 
6. Boukri, M.; Farsi, M.N.; Mebarki, A.; Belazougui, M.; Ait-Belkacem, M.; Yousfi, N.; Guessoum, N.; Benamar, D.A.; Naili, M.; Mezouar, N.; et al. Seismic vulnerability assessment at urban scale: Case of Algerian buildings. Int. J. Disaster Risk Reduct. 2018, 31, 555-575. [CrossRef]

7. Akinola, O.V.; Adegoke, J. Assessment of forest fire vulnerability zones in Missouri, United States of America. Int. J. Sustain. Dev. World Ecol. 2019, 26, 251-257. [CrossRef]

8. Dabanli, I. Drought hazard, vulnerability, and risk assessment in Turkey. Arab. J. Geosci. 2018, 11, 1-12. [CrossRef]

9. Granda, S.; Ferreira, T.M. Assessing Vulnerability and Fire Risk in Old Urban Areas: Application to the Historical Centre of Guimarães. Fire Technol. 2019, 55, 105-127. [CrossRef]

10. Lee, H.J.; Kim, J.Y.; Kim, M.Y.; Sung, H.P. Risk Assessment of Chemical Accidents Using Atmospheric Dispersion Modeling. J. Korean Soc. Environ. Technol. 2018, 19, 305-313. [CrossRef]

11. Basheer, A.; Tauseef, S.M.; Abbasi, T.; Abbasi, S.A. A template for quantitative risk assessment of facilities storing hazardous chemicals. Int. J. Syst. Assur. Eng. Manag. 2019, 10, 1158-1172. [CrossRef]

12. Bondžić, J.; Sremački, M.; Popov, S.; Mihajlović, I.; Vujić, B.; Petrović, M. Exposure to hazmat road accidents-Toxic release simulation and GIS-based assessment method. J. Environ. Manag. 2021, 293, 112941. [CrossRef]

13. Guinet, A.; Faccincani, R. Hospital's vulnerability assessment. In Proceedings of the 2015 International Conference on Industrial Engineering and Systems Management (IESM), Seville, Spain, 21-23 October 2015; IEEE: New York, NY, USA, 2015.

14. Azari, P.; Karimi, M. Extracting spatial patterns of urban gas pipeline risk considering social and structural parameters of urban blocks. J. Nat. Gas. Sci. Eng. 2018, 55, 16-29. [CrossRef]

15. Gromek, P.; Sobolewski, G. Risk-Based Approach for Informing Sustainable Infrastructure Resilience Enhancement and Potential Resilience Implication in Terms of Emergency Service Perspective. Sustainability 2020, 12, 4530. [CrossRef]

16. Moradi, A.; Bidhendi, G.R.A.N.; Safavi, Y. Efective environment indicators on improving the resilience of Mashhad neighborhoods. Int. J. Environ. Sci. Technol. 2021, 18, 2441-2458. [CrossRef]

17. Feofilovs, M.; Romagnoli, F. Dynamic assessment of urban resilience to natural hazards. Int. J. Disaster Risk Reduct. 2021, 62, 102328. [CrossRef]

18. Cardoso, M.A.; Brito, R.S.; Pereira, C.; Gonzalez, A.; Stevens, J.; Telhado, M.J. RAF Resilience Assessment Framework-A Tool to Support Cities' Action Planning. Sustainability 2020, 12, 2349. [CrossRef]

19. Ottai, N.B. Capacity Assessment Framework to Enhance Disaster Resilience within Kingdom of Saudi Arabia; University of Salford: Manchester, UK, 2017.

20. Yang, Y.; Yan, A.; Wang, G.; Hou, R.; Cheng, B. Study on Urban Emergency Response Capacity Evaluation Index System. China Emerg. Rescue 2019, 6, 32-35.

21. Arambepola, N.M.S.I.; Rahman, M.A.; Tawhid, K. Planning Needs Assessment for Responding to Large Disaster Events in Cities: Case Study from Dhaka, Bangladesh. Procedia Econ. Financ. 2014, 18, 684-692. [CrossRef]

22. Chisty, M.A.; Rahman, M.M. Coping capacity assessment of urban fire disaster: An exploratory study on ward no: 30 of Old Dhaka area. Int. J. Disaster Risk Reduct. 2020, 51, 101878. [CrossRef]

23. Anantsuksomsri, S.; Tontisirin, N. Assessment of Natural Disaster Coping Capacity from Social Capital Perspectives: A Case Study of Bangkok. J. Disaster Res. 2020, 15, 571-578. [CrossRef]

24. Zhao, D.; Chen, C.; Yi, L. Research on multi-hazard comprehensive risk assessment of public safety in regional urban agglomerations. J. Saf. Sci. Technol. 2020, 16, 30-36.

25. Zhou, S.; Zhai, G.; Shi, Y.; Lu, Y. A Literature Review of Urban Natrual Disaster Risk Assessment. J. Catastr. $2020,35,180-186$.

26. Tiepolo, M.; Bacci, M.; Braccio, S.; Bechis, S. Multi-Hazard Risk Assessment at Community Level Integrating Local and Scientific Knowledge in the Hodh Chargui, Mauritania. Sustainability 2019, 11, 5063. [CrossRef]

27. Khatakho, R.; Gautam, D.; Aryal, K.R.; Pandey, V.P.; Rupakhety, R.; Lamichhane, S.; Liu, Y.; Abdouli, K.; Talchabhadel, R.; Thapa, B.R.; et al. Multi-Hazard Risk Assessment of Kathmandu Valley, Nepal. Sustainability 2021, 13, 5369. [CrossRef]

28. Gallina, V.; Torresan, S.; Zabeo, A.; Critto, A.; Glade, T.; Marcomini, A. A Multi-Risk Methodology for the Assessment of Climate Change Impacts in Coastal Zones. Sustainability 2020, 12, 3697. [CrossRef]

29. Barría, P.; Cruzat, M.L.; Cienfuegos, R.; Gironás, J.; Escauriaza, C.; Bonilla, C.; Moris, R.; Ledezma, C.; Guerra, M.; Rodríguez, R.; et al. From Multi-Risk Evaluation to Resilience Planning: The Case of Central Chilean Coastal Cities. Water 2019, 11, 572. [CrossRef]

30. Depietri, Y.; Dahal, K.; McPhearson, T. Multi-hazard risks in New York City. Nat. Hazards Earth Syst. Sci. 2018, $18,3363-3381$. [CrossRef]

31. Bixler, R.P.; Yang, E.; Richter, S.M.; Coudert, M. Boundary crossing for urban community resilience: A social vulnerability and multi-hazard approach in Austin, Texas, USA. Int. J. Disaster Risk Reduct. 2021, 66, 102613. [CrossRef]

32. Araya-Muñoz, D.; Metzger, M.J.; Stuart, N.; Wilson, A.M.W.; Carvajal, D. A spatial fuzzy logic approach to urban multi-hazard impact assessment in Concepción, Chile. Sci. Total Environ. 2017, 576, 508-519. [CrossRef]

33. Tang, L.; Chen, X. Development Techniques of Enterprise WebGIS Application. China Data Commun. 2005, 7, $28-34$.

34. Dolce, M.; Speranza, E.; Giordano, F.; Borzi, B.; Bocchi, F.; Conte, C.; Meo, A.D.; Faravelli, M.; Pascale, V. Observed damage database of past Italian earthquakes: The Da.D.O. WebGIS. Bull. Geophys. Oceanogr. 2019, 60, 141-164.

35. Abdalla, R.; Elawad, Y.; Chen, Z.; Han, S.S.; Xia, R. A GIS-supported fuzzy-set approach for flood risk assessment. Can. Water Resour. J. 2014, 39, 3-14. [CrossRef] 
36. Cui, B.; Zhou, Z.; Wang, X.; Sun, M.; Sun, X. System Development for Storm Surge Hazard Assessment Based on WebGIS for Tianjin Binhai New Area. Trans. Tianjin Univ. 2016, 22, 50-56. [CrossRef]

37. Azevedo, A.; Fortunato, A.B.; Epifânio, B.; den Boer, S.; Oliveira, E.R.; Alves, F.L.; de Jesus, G.; Gomes, J.L.; Oliveira, A. An oil risk management system based on high-resolution hazard and vulnerability calculations. Ocean. Coast. Manag. 2017, 136, 1-18. [CrossRef]

38. Giovinazzi, S.; Marchili, C.; Di Pietro, A.; Giordano, L.; Costanzo, A.; Porta, L.L.; Pollino, M.; Rosato, V.; Lückerath, D.; Milde, K.; et al. Assessing Earthquake Impacts and Monitoring Resilience of Historic Areas: Methods for GIS Tools. ISPRS Int. J. Geo-Inf. 2021, 10, 461. [CrossRef]

39. Coletti, A.; De Nicola, A.; Di Pietro, A.; La Porta, L.; Pollino, M.; Rosato, V.; Vicoli, G.; Villani, M.L. A comprehensive system for semantic spatiotemporal assessment of risk in urban areas. J. Conting. Crisis Manag. 2020, 28, 178-193. [CrossRef]

40. Chen, G.; Yang, Q.; Chen, X.; Huang, K.; Zeng, T.; Yuan, Z. Methodology of Urban Safety and Security Assessment Based on the Overall Risk Management Perspective. Sustainability 2021, 13, 6560. [CrossRef]

41. Kolios, S.; Stylios, C.; Petunin, A. A WebGIS platform to monitor environmental conditions in ports and their surroundings in South Eastern Europe. Environ. Monit. Assess. 2015, 187, 574. [CrossRef]

42. Singh, A.; Chawla, P.; Singh, K.; Singh, A.K. Formulating an MVC Framework for Web Development in JAVA. In Proceedings of the 2018 2nd International Conference on Trends in Electronics and Informatics (ICOEI), Tirunelveli, India, 11-12 May 2018; IEEE: New York, NY, USA, 2018.

43. United Nations Office for Disaster Risk Reduction. Global Assessment Report on Disaster Risk Reduction. 2019. Available online: https: / / gar.undrr.org/report-2019 (accessed on 10 May 2021).

44. United Nations Office for Disaster Risk Reduction. Sendai Framework for Disaster Risk Reduction 2015-2030. 2015. Available online: http:/ / www.cma.gov.cn/en2014/20150311/20151010/2015101002/201510/P020151012525690375817.pdf (accessed on 10 May 2021).

45. United Nations Office for Disaster Risk Reduction. Open-Ended Intergovernmental Expert Working Group on Indicators and Terminology Relating to Disaster Risk Reduction. 2016. Available online: https://www.unisdr.org/files/47136_ reportsecondsessionoiewg.pdf (accessed on 10 May 2021). 